\title{
Cardiac $\mathrm{Ca}_{\mathrm{v}} 1.2$ channels require $\beta$ subunits for $\beta$-adrenergic-mediated modulation but not trafficking
}

\author{
Lin Yang, ${ }^{1}$ Alexander Katchman, ${ }^{1}$ Jared Kushner, ${ }^{1}$ Alexander Kushnir, ${ }^{1}$ Sergey I. Zakharov, ${ }^{1}$ Bi-xing Chen, ${ }^{1}$ Zunaira Shuja, ${ }^{2}$ \\ Prakash Subramanyam, ${ }^{2}$ Guoxia Liu, ${ }^{1}$ Arianne Papa, ${ }^{2}$ Daniel Roybal, ${ }^{3}$ Geoffrey S. Pitt, ${ }^{4}$ Henry M. Colecraft, ${ }^{2,3}$ and Steven 0. Marx ${ }^{1,3}$ \\ 'Division of Cardiology, Department of Medicine, Columbia University, ²Department of Physiology and Cellular Biophysics, and ${ }^{3}$ Department of Pharmacology, Vagelos College of Physicians and Surgeons, \\ New York, New York, USA. ${ }^{4}$ Cardiovascular Research Institute, Weill Cornell Medical College, New York, New York, USA.
}

\begin{abstract}
$\mathrm{Ca}^{2+}$ channel $\beta$-subunit interactions with pore-forming $\alpha$-subunits are long-thought to be obligatory for channel trafficking to the cell surface and for tuning of basal biophysical properties in many tissues. Unexpectedly, we demonstrate that transgenic expression of mutant $\alpha_{1 c}$ subunits lacking capacity to bind $\mathrm{Ca}_{v} \beta$ can traffic to the sarcolemma in adult cardiomyocytes in vivo and sustain normal excitation-contraction coupling. However, these $\beta$-less $\mathrm{Ca}^{2+}$ channels cannot be stimulated by $\beta$-adrenergic pathway agonists, and thus adrenergic augmentation of contractility is markedly impaired in isolated cardiomyocytes and in hearts. Similarly, viral-mediated expression of a $\beta$-subunit-sequestering peptide sharply curtailed $\beta$-adrenergic stimulation of WT $\mathrm{Ca}^{2+}$ channels, identifying an approach to specifically modulate $\beta$-adrenergic regulation of cardiac contractility. Our data demonstrate that $\beta$ subunits are required for $\beta$-adrenergic regulation of $\mathrm{Ca}_{\mathrm{v}} 1.2$ channels and positive inotropy in the heart, but are dispensable for $\mathrm{Ca}_{\mathrm{v}} \mathrm{1.2}$ trafficking to the adult cardiomyocyte cell surface, and for basal function and excitation-contraction coupling.
\end{abstract}

\section{Introduction}

In heart cells, $\mathrm{Ca}^{2+}$ influx via $\mathrm{Ca}_{\mathrm{v}} 1.2$ channels mediates excitation-contraction (E-C) coupling, controls action potential duration, and regulates gene expression. $\mathrm{Ca}_{\mathrm{v}} 1.2$ channels are multi-subunit proteins composed minimally of a pore-forming $\alpha_{1 C}$ and regulatory $\beta$ and $\alpha_{2} \delta$ subunits (1-4). In adult ventricular cardiomyocytes, most $\mathrm{Ca}_{\mathrm{v}} 1.2$ channels localize to transverse tubules where they lie in close proximity $(\sim 12 \mathrm{~nm})$ and apposed to ryanodine receptors (RyR2) at dyadic junctions (5). Dysregulation of $\mathrm{Ca}_{\mathrm{v}} 1.2$ activity, surface density, or subcellular localization in cardiomyocytes can result in cardiac arrhythmias, heart failure, and sudden death.

Reconstitution experiments concluded that binding to $\beta$ subunits is indispensable for $\alpha_{1 \mathrm{C}}$ trafficking to the cell surface (6-14). The physiological relevance of this finding was initially supported by $\beta_{2}$ knockout mice, which were embryonic lethal, likely secondary to a decreased L-type $\mathrm{Ca}^{2+}$ current (15). An initial idea that $\beta$ binding to the $\underline{\alpha}$-interaction domain (AID) of the $\alpha_{1}$-subunit I-II loop shielded an ER retention signal in the I-II loop to allow forward trafficking of the channel proved inadequate in subsequent experiments $(9,16-18)$. Surprisingly, cardiomyocyte-specific, conditional deletion of the Cacnb2 gene in adult mice reduced $\beta_{2}$ protein by $96 \%$ but caused only a modest $29 \%$ reduction in $\mathrm{Ca}^{2+}$ current, with no obvious cardiac impairment (19). Interpretation

\section{Related Commentary: p. 496}

\footnotetext{
Authorship note: LY, A. Katchman, JK, and A. Kushnir contributed equally to this work Conflict of interest: The authors have declared that no conflict of interest exists. License: Copyright 2019, American Society for Clinical Investigation.

Submitted: July 30, 2018; Accepted: November 6, 2018.

Reference information: J Clin Invest. 2019;129(2):647-658.

https://doi.org/10.1172/JCl123878.
}

of this result is ambiguous, however, as it is complicated by the remnant $(\sim 4 \%) \beta_{2}$ expression as well as the presence other $\mathrm{Ca}_{\mathrm{v}} \beta$ isoforms expressed in adult cardiomyocytes (13). Moreover, a contrasting viewpoint was provided by a study in which shRNA-mediated knockdown of $\beta_{2}$ in adult rat myocytes substantially diminished $\mathrm{Ca}^{2+}$ current (20).

To definitively address the controversies regarding the role of $\beta$ subunits in mediating trafficking and regulation of $\mathrm{Ca}^{2+}$ channels in the heart, we created transgenic mice lines with 3 mutations in the AID, which renders the pore-forming $\alpha_{1 C}$ subunit incapable of binding $\beta$ subunits. With this new model, we definitively demonstrate in vivo that $\beta$ subunit binding to $\alpha_{1 C}$ is not required for trafficking and that the basal function of $\beta$-less $\mathrm{Ca}^{2+}$ channels is only minimally altered.

Instead, we found that the $\beta$ subunit is obligatory for transducing $\beta$-adrenergic signals to cardiac $\mathrm{Ca}_{\mathrm{v}} 1.2$ channels. Cardiac $\mathrm{Ca}_{\mathrm{v}} 1.2$ channels are prominently upregulated by $\beta$-adrenergic agonists via activation of protein kinase A (PKA) $(21,22)$ as part of the fundamental flight-or-fight response, yet the detailed mechanisms by which PKA activates $\mathrm{Ca}_{\mathrm{v}} 1.2$ remain unknown despite several decades of investigation. Recently, we reported that alanine substitution of all consensus, conserved PKA phosphorylation sites (> 22 serines/ threonines) in the $\alpha_{1 \mathrm{C}}$ subunit did not affect adrenergic regulation of CaV1.2 in vivo (23). Prior studies also ruled out a contribution for the $\beta$ subunit, as substitution or elimination of potential PKA phosphorylation sites did not perturb $\beta$-adrenergic regulation (24-27), although other consensus PKA sites are present in the N-terminal regions of the protein. We found that $\beta$ subunit binding to $\alpha_{1 \mathrm{C}}$, but not PKA phosphorylation of $\beta$, is absolutely essential for the augmentation of $\mathrm{Ca}^{2+}$ current and cardiac contractile response to $\beta$-adrenergic PKA stimulation. These findings identify the key regulatory mechanisms impacting $\beta$-adrenergic regulation of $\mathrm{Ca}^{2+}$ influx and contractility in the heart. 
A

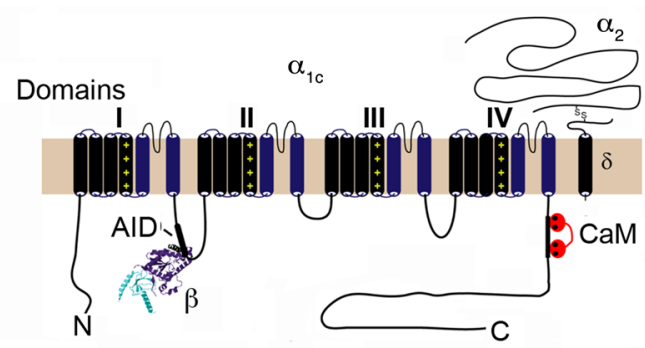

WT:

QQLEEDLKGYLDWITQAE

AIDmut : QQLEEDLKGALDAATQAE

C

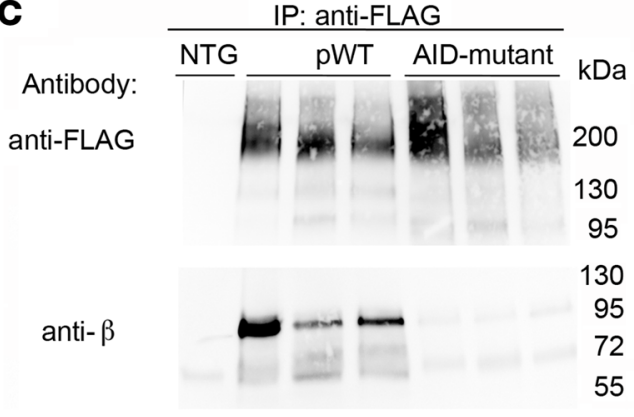

E
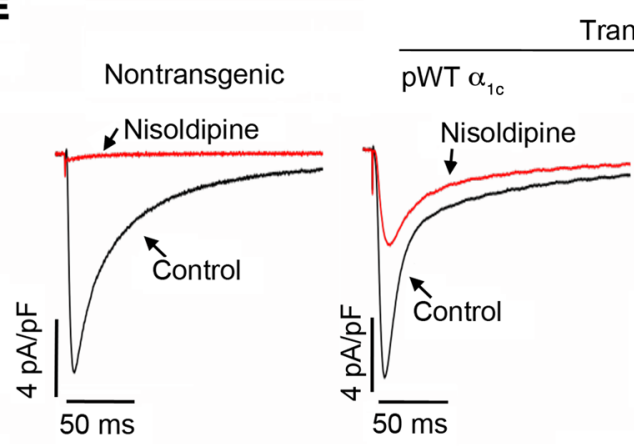

Transgenic

AID-mutant $\alpha_{1 c}$

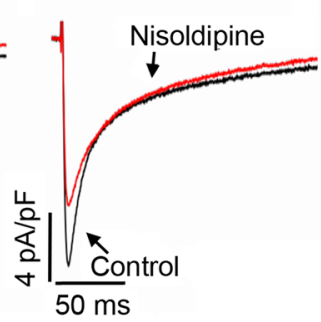

D
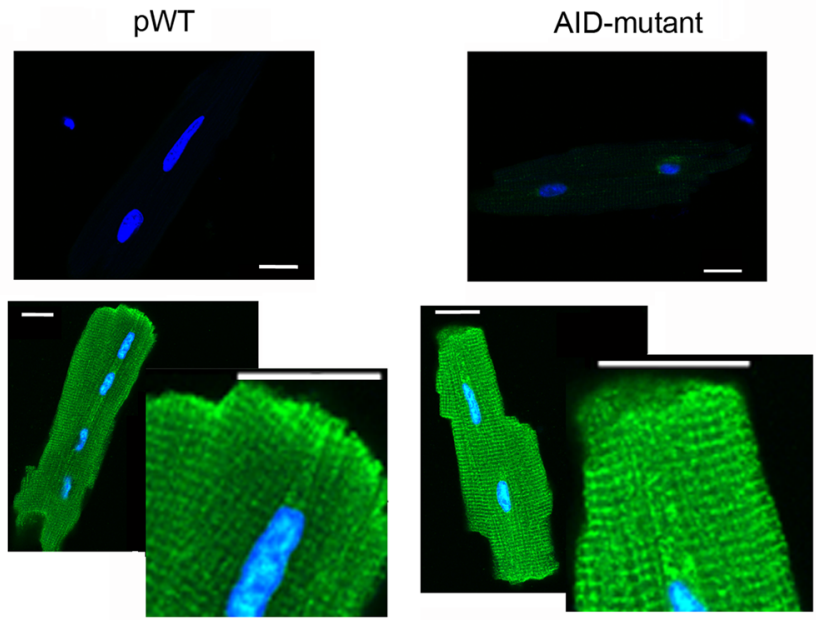

$\mathbf{F}$

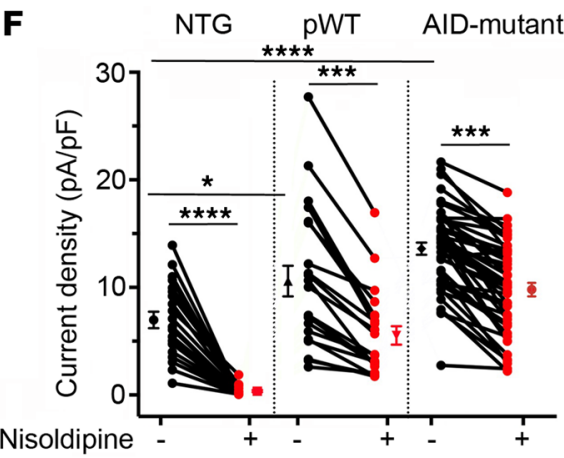

G

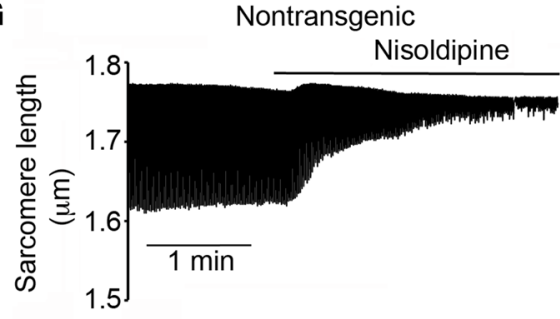

I

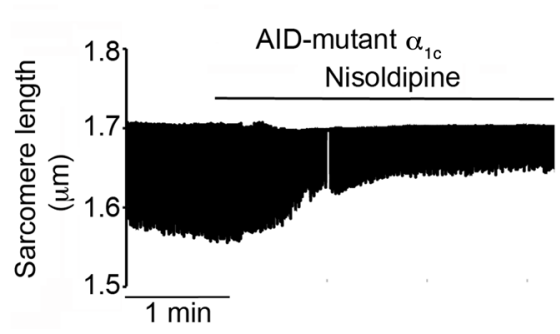

H

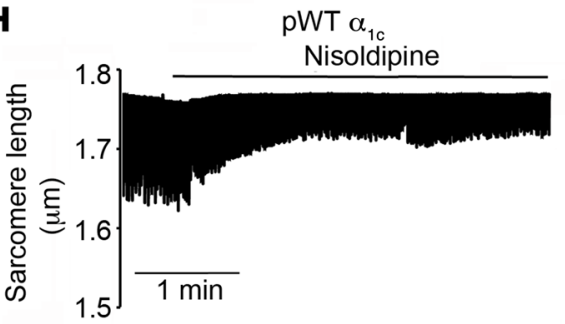

J

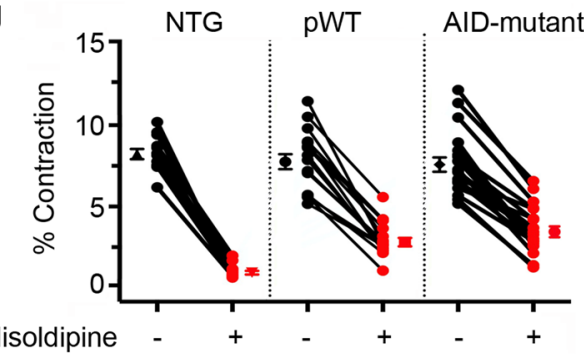


Figure 1. AID-mutant $\alpha_{1 c}$ channels trafficking and function in cardiomyocytes. (A) Schematic of rabbit cardiac $\alpha_{1 c}$ subunit topology showing $\beta$-subunit binding to $\underline{\alpha}$-interacting domain (AID) motif in I-II loop. WT and mutant-AID motif in the I-II loop of $\alpha_{1 C}$ (B) Schematic representation of the binary transgene system. The $\alpha M H C_{M 0 D}$ construct is a modified $\alpha \mathrm{MHC}$ promoter containing the tet-operon for regulated expression of FLAG-tagged DHP-resistant (DHP*) $\alpha_{1 c}$. (C) Anti-FLAG (upper) and anti- $\beta$ immunoblots (lower) of anti-FLAG antibody immunoprecipitation of cardiac homogenates of nontransgenic (NTC), pWT $\alpha_{1 c}$, and AID-mutant $\alpha_{1 C}$ mice. Representative of 3 experiments. (D) Immunostaining of pWT and AID-mutant $\alpha_{1 C}$ cardiomyocytes. Anti-FLAG and FITC-conjugated secondary antibodies, and nuclear labeling with Hoechst stain. Negative control omitted anti-FLAG antibody. Images obtained with confocal microscopy at $\times 40$. Scale bars: $20 \mu \mathrm{m}$. (E) Exemplar whole-cell $\mathrm{Ca}_{\mathrm{v}} 1.2$ currents recorded from freshly dissociated cardiomyocytes of NTG, pWT, and AID-mutant $\alpha_{1 c}$ transgenic mice. Pulses from $-60 \mathrm{mV}$ to $0 \mathrm{mV}$ before (black traces) and 3 minutes after (red traces) administration of $300 \mathrm{nM}$ nisoldipine. (F) Scatter plot showing current densities before and after administration of $300 \mathrm{nM}$ nisoldipine. Mean \pm SEM. ${ }^{*} P<0.05$ NTG versus transgenic pWT $\alpha_{11},{ }^{* * *} P$ $<0.0001$ NTG versus transgenic AID-mutant $\alpha_{1 c}$ and also NTC pre- versus post-nisoldipine, ${ }^{* *} P<0.001 \mathrm{pWT}$ or AID-mutant $\alpha_{1 \mathrm{C}}$ pre- versus postnisoldipine. One-way ANOVA and Dunnett's multiple comparison test. NTG, $n=8$ cardiomyocytes from 5 mice; pWT, $n=21$ cardiomyocytes from 7 mice; AID-mutant, $n=45$ cardiomyocytes from 9 mice. (G-I) Representative time courses of changes in sarcomere length after superfusion of $300 \mathrm{nM}$ nisoldipine-containing solution for cardiomyocytes isolated from NTC mice (C) and pWT (H) and AID-mutant transgenic $\alpha_{1 C}$ mice. Cardiomyocytes were field-stimulated at $1 \mathrm{~Hz}$. (J) Scatter plot showing percentage of contraction of sarcomere length in the absence and presence of nisoldipine for cardiomyocytes isolated from NTC mice and pWT and AID-mutant $\alpha_{1 \mathrm{C}}$ transgenic mice. NTG, $n=12$ cells from 3 mice; $\mathrm{pWT}$, $n=16$ cells from 3 mice; AID-mutant, $n=18$ cells from 3 mice.

\section{Results}

$\beta$-less $C a_{V} 1.2$ channels traffic to membrane in adult cardiomyocytes. Alanine substitutions of 3 conserved residues-Y467, W470, and I471in rabbit $\alpha_{1 \mathrm{C}}$ AID (Figure 1A) increases the $K_{D}$ of $\beta$ subunit binding from $5 \mathrm{nM}$ to greater than $6 \mathrm{M}(28-31) . \beta_{2}$ subunits failed to coprecipitate with the AID-mutant $\alpha_{1 \mathrm{C}}$ when coexpressed with AID-mutant $\alpha_{1 \mathrm{C}}$ in tsA201 cells (Supplemental Figure 1A; supplemental material available online with this article; https://doi.org/10.1172/ JCI123878DS1) confirming the critical importance of this region for $\beta$ binding. We then created transgenic mice with cardiac-specific and doxycycline-inducible expression of N-terminal 3X-FLAG-tagged dihydropyridine-resistant (DHP-resistant) (T1066Y/Q1070M) $(32,33)$ AID-mutant rabbit $\alpha_{1 \mathrm{C}}$ (Figure 1B). Controls were provided by transgenic FLAG-tagged DHP-resistant $\alpha_{1 \mathrm{C}}$ subunits with WT AIDs, termed pseudo-WT (pWT) $\alpha_{1 C}$. Coimmunoprecipitation experiments from transgenic mice hearts confirmed that $\mathrm{pWT} \alpha_{1 \mathrm{C}}$ associates with endogenous $\beta$ subunit, but AID-mutant $\alpha_{1 \mathrm{C}}$ does not (Figure $1 \mathrm{C}$ ). The anti $-\beta$ antibody recognizes all $\mathrm{Ca}_{\mathrm{v}} \beta$ subunits, thus ruling out compensation from other $\beta$ subunits in heart and thus confirming that the AID motif is essential to mediate the high-affinity binding between $\alpha_{1 \mathrm{C}}$ and $\beta_{2}$ in cardiomyocytes.

We assessed the impact of loss of $\beta$ binding on AID-mutant $\alpha_{1 \mathrm{C}}$ subcellular localization and functional expression in cardiomyocytes using 3 complementary approaches. First, immunofluorescence experiments using anti-FLAG antibody on fixed cardiomyocytes indicated that both transgenic pWT $\alpha_{1 \mathrm{C}}$ and AID-mutant $\alpha_{1 \mathrm{C}}$ channels displayed a similar striated pattern consistent with surface membrane distribution and localization in transverse tubules (Figure 1D). Second, we exploited the T1066Y/ Q1070M mutations that impart relative DHP-resistance $(32,33)$ to block $\mathrm{Ca}^{2+}$ currents from endogenous DHP-sensitive $\mathrm{Ca}_{\mathrm{v}} 1.2$ with nisoldipine and isolate $\mathrm{Ca}^{2+}$ current from transgenic pWT $\alpha_{1 \mathrm{C}}$ or AID-mutant $\alpha_{1 \mathrm{C}}$ channels. Compared with cardiomyoctes isolated from NTG control mice, cardiomyocytes isolated from both pWT and AID-mutant $\alpha_{1 \mathrm{C}}$ transgenic mice had increased peak $\mathrm{Ca}^{2+}$ currents, and substantial peak $\mathrm{Ca}^{2+}$ currents remaining after exposure to nisoldipine (Figure 1, E and F). Third, field-stimulated contraction of cardiomyocytes isolated from transgenic AID-mutant $\alpha_{1 \mathrm{C}}$ mice persisted in the presence of $300 \mathrm{nM}$ nisoldipine (Figure 1, I and J), similar to the contraction of cardiomyocytes isolated from transgenic pWT $\alpha_{1 \mathrm{C}}$ mice in the presence of nisoldipine. Contraction of cardiomyoyctes isolated from NTG was markedly inhibited by nisoldipine (Figure 1, G and H). Overall, these results demonstrate that transgenic $\beta$-less AID-mutant $\alpha_{1 \mathrm{C}}$ channels traffic to the sarcolemma and trigger E-C coupling in cardiomyocytes. This is in stark contrast to the necessary role of $\beta$ binding for surface trafficking and function of $\mathrm{Ca}_{\mathrm{v}} 1.2$ channels reconstituted in heterologous cells (Supplemental Figure 1, A and B), or expressed in hippocampal neurons (34).

We also considered that endogenous WT $\alpha_{1 \mathrm{C}}$ channels could couple with AID-mutant $\alpha_{1 C}$ channels to facilitate trafficking of $\beta$-less channels to the surface membranes in cardiomyocytes, which could be the basis for the observed differences between cardiomyocytes and heterologous expression systems. To determine whether coupling-induced trafficking could occur, we coexpressed either DHP-resistant pWT $\alpha_{1 \mathrm{C}}$ or DHP-resistant AID-mutant $\alpha_{1 \mathrm{C}}$ with both WT $\alpha_{1 C}$ and $\beta_{2}$ subunits in tsA201. In the presence of nisoldipine, which inhibits the WT $\alpha_{1 \mathrm{C}}$ channels, tsA201 cells expressing the AID-mutant $\alpha_{1 \mathrm{C}}$ channels had no remaining $\mathrm{Ca}^{2+}$ current (Supplemental Figure 1C, right), whereas cells expressing the DHP-resistant pWT $\alpha_{1 \mathrm{C}}$ had remaining current (Supplemental Figure 1C, left), implying that at least in tsA201 cells, $\beta$-less channels were unable to "hitchhike" to the membrane with WT channels.

PKA modulation of $C a_{V} 1.2$ channels is dependent on $\alpha_{1 C}-\beta$ interactions. In heterologous expression studies, $\beta$ subunits not only enable $\alpha_{1 \mathrm{C}}$ surface trafficking, but also can differentially induce, depending on $\beta$ subunit isoform, a hyperpolarizing shift in the voltage dependence of $\mathrm{Ca}_{\mathrm{v}} 1.2$ activation and increase the channel open probability $\left(P_{\mathrm{o}}\right)(12,27)$. We assessed the biophysical properties of the transgenic $\beta$-less AID-mutant $\alpha_{1 C}$ channels compared with transgenic pWT $\mathrm{Ca}^{2+}$ channels. Surprisingly, normalized current-voltage $(I-V)$ relationships of nisoldipine-resistant transgenic pWT and AID-mutant $\alpha_{1 C}$ channels were remarkably similar (Figure 2A). The midpoint potentials, derived from a Boltzmann function, for steady-state activation demonstrated a small, nonsignificant 1-mV hyperpolarizing shift for the AID-mutant channels compared with control pWT channels (Figure 2B), whereas the slope factors for the 2 channel types were not different (Figure 2C). Furthermore, the inactivation kinetics of nisoldipine-resistant $\mathrm{Ca}^{2+}$ currents were not significantly different at any test potential between cardiomyocytes isolated from pWT and AID-mutant $\alpha_{1 C}$, respectively (Figure 2D). Therefore, in adult cardiomyocytes, $\mathrm{Ca}_{\mathrm{v}} 1.2$ channels comprised of transgenic $\beta$-less $\alpha_{1 \mathrm{C}}$ have similar voltage dependence of activation and inactivation kinetics as transgenic $\mathrm{pWT} \mathrm{Ca}_{\mathrm{v}} 1.2$ channels. 
A

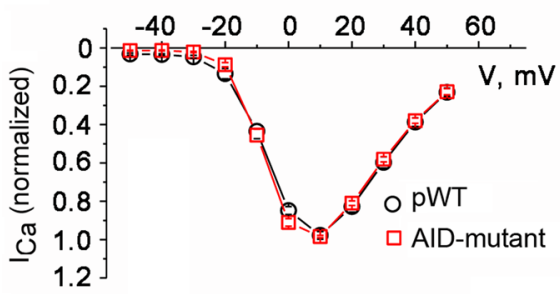

D $\quad$ pWT - AID-mutant

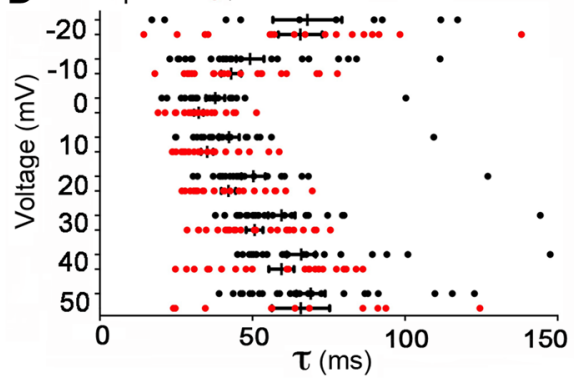

$\mathbf{F}$

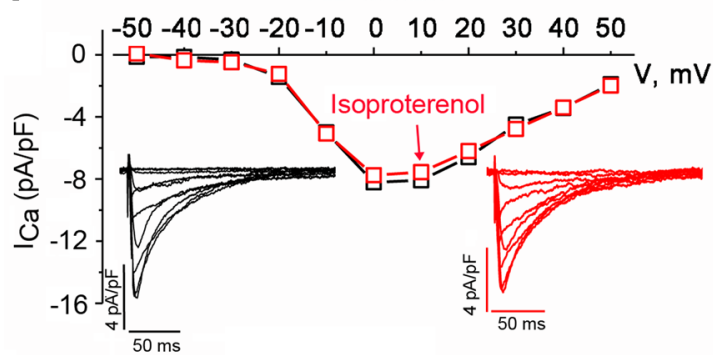

H

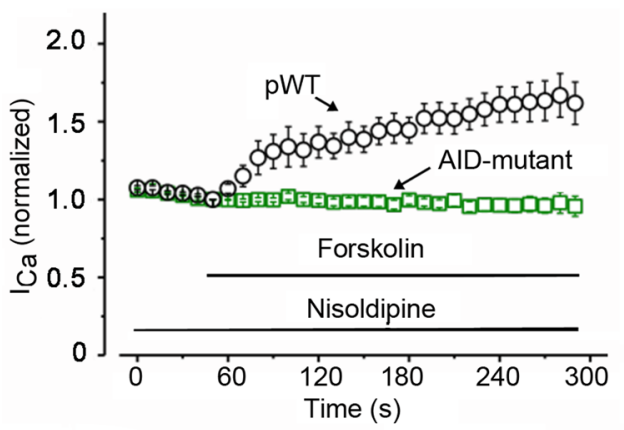

J

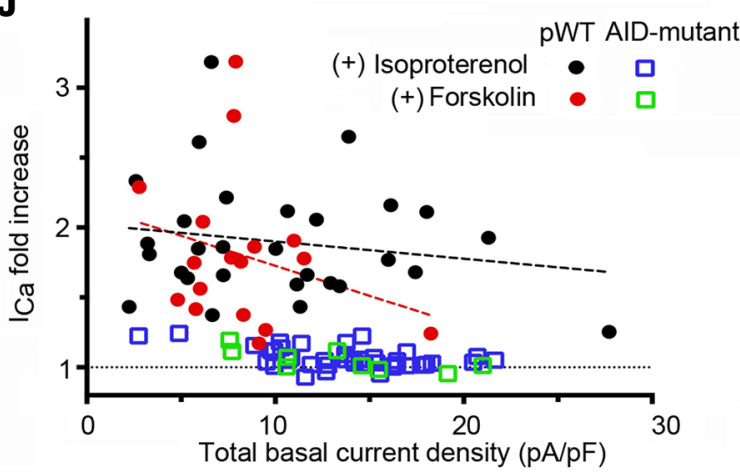

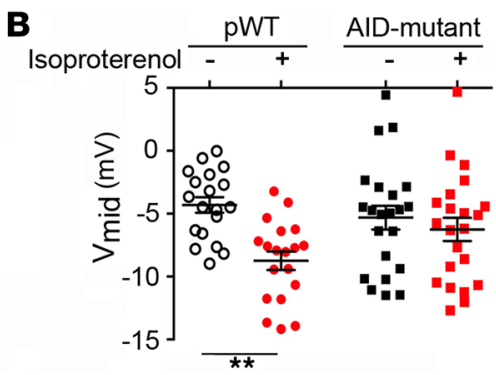

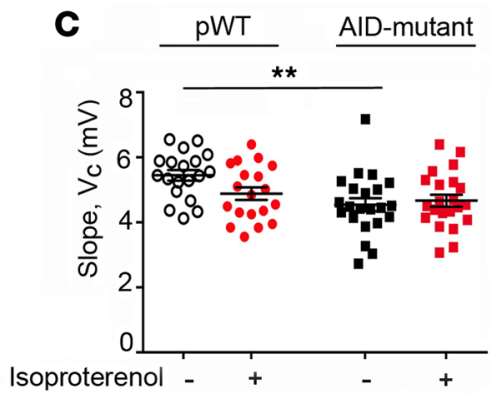

E

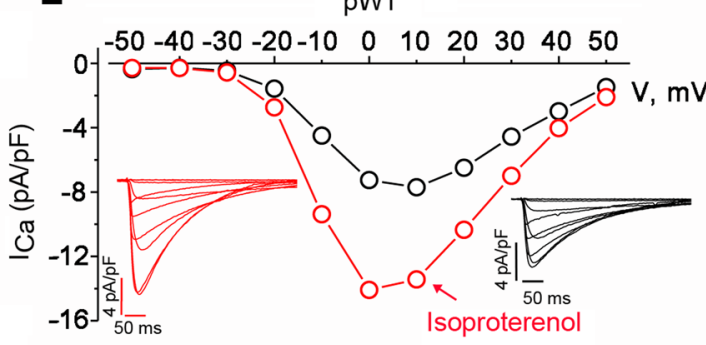

G

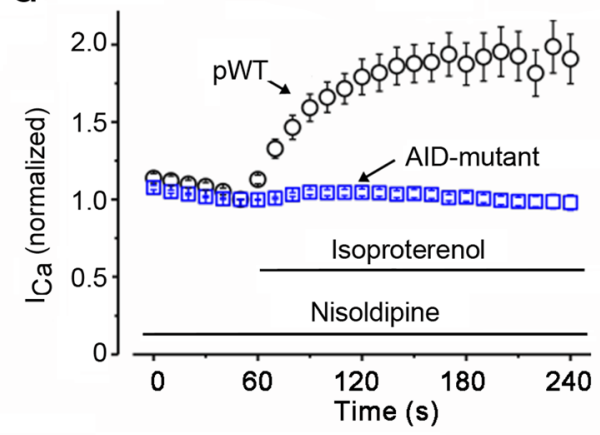

I

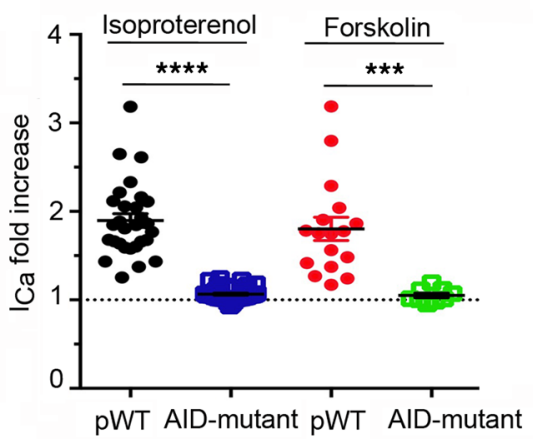


Figure 2. AID-mutant $\mathrm{Ca}_{\mathrm{v}} 1.2$ channels lack $\boldsymbol{\beta}$-adrenergic regulation. (A) Normalized $\mathrm{Ca}_{\mathrm{v}} 1.2$ current-voltage relationships for transgenic $\mathrm{pWT}$ and AID-mutant $\alpha_{1 C}$ cardiomyocytes in the presence of nisoldipine $(n=19$ cardiomyocytes from $3 \mathrm{pWT} \alpha_{1 c}$ transgenic mice; $n=18$ cardiomocytes from 6 AID-mutant $\alpha_{1 c}$ transgenic mice). (B and $\mathbf{C}$ ) Bar graphs of Boltzmann function parameters $V_{\text {mid }}$ and slope $\left(V_{c}\right)$. ${ }^{* *} P<0.01$, ANOVA and Sidak's multiple comparison test; $n=19$ cardiomyocytes from $3 \mathrm{pWT} \alpha_{1 c}$ transgenic mice; $n=18$ cardiomocytes from 6 AID-mutant $\alpha_{1 c}$ transgenic mice. (D) Summary of time constants of inactivation at the indicated potentials obtained from a single exponential fit ( $n=24 \mathrm{pWT} \alpha_{1 c}$ cardiomyocytes from 4 mice and $n=24$ AID-mutant $\alpha_{1 c}$ cardiomyocytes from 4 mice). $P>0.05$ pWT versus AID-mutant for all voltages using Sidak's multiple comparison test. ( $\mathbf{E}$ and $\mathbf{F}$ ) Exemplar nisoldipine-resistant current-voltage relationships of transgenic pWT $\alpha_{1 \mathrm{C}}(\mathbf{E})$ and AID-mutant $\alpha_{1 \mathrm{C}}(\mathbf{F})$ acquired in the absence (black trace) and presence of $200 \mathrm{nM}$ isoproterenol (red trace). (C) Diary plot of normalized nisoldipine-resistant $I_{\mathrm{ca}}$ amplitude at $0 \mathrm{mV}$ (normalized to 1 at 50 seconds prior to isoproterenol) of pWT and AID-mutant $\alpha_{1 c}$ cardiomyocytes. Cells exposed to $300 \mathrm{nM}$ nisoldipine followed by $200 \mathrm{nM}$ isoproterenol in the continued presence of nisoldipine. pWT, $n=30$ cardiomyocytes from 5 mice; AID-mutant, $n=45$ cardiomyocytes from 7 mice. $P<0.0001$ by 1-way ANOVA/multiple comparison at all time points 30 seconds after isoproterenol. (H) Diary plot of normalized nisoldipine-resistant $I_{\text {Ca }}$ amplitude at $+10 \mathrm{mV}$ (normalized to 1 at 50 seconds, prior to forskolin) of pWT and AID-mutant $\alpha_{1 c}$ cardiomyocytes. Cells exposed to $300 \mathrm{nM}$ nisoldipine followed by $10 \mu \mathrm{M}$ forskolin in the continued presence of nisoldipine. pWT: $n$ $=15$ cardiomyocytes from 2 mice; AID-mutant: $n=20$ cardiomyocytes from 6 mice. $P<0.0001$ by 1 -way ANOVA/multiple comparison at all time points 30 seconds after forskolin. (I) Bar graph of isoproterenol- or forskolin-induced fold increase in nisoldipine-resistant $\mathrm{I}_{\mathrm{Ca}}$. Mean $\pm \mathrm{SEM}$. ${ }^{* *} P<0.001$; ${ }^{* * * *} P<0.0001$ by $t$ test. (J) Graph of isoproterenol- and forskolin-induced increase in nisoldipine-resistant current stratified by total basal current density before nisoldipine for $\mathrm{PWT} \alpha_{1 c}$ and AID-mutant $\alpha_{15}$ transgenic mice. Lines fitted by linear regression for pWT cells for isoproterenol (black) and forskolin (red). For isoproterenol, pWT $\alpha_{1 c}, n=29$ cardiomyocytes; AID-mutant $\alpha_{1,}, n=45$ cardiomyocytes. For forskolin, pWT $\alpha_{1 c}, n=17$ cardiomyocytes; AID-mutant $\alpha_{1 c}, n=9$ cardiomyocytes.

We next determined the sensitivity of $\mathrm{Ca}_{\mathrm{v}} 1.2$ channels containing either transgenic pWT $\alpha_{1 \mathrm{C}}$ or AID-mutant $\alpha_{1 \mathrm{C}}$ to PKA modulation. In cardiomyocytes isolated from mice expressing transgenic pWT $\alpha_{1 c}, 200 \mathrm{nM}$ isoproterenol increased the nisoldipine-insensitive current by a mean of 1.9-fold \pm 0.1 -fold (Figure 2, E-J), and shifted the $\mathrm{V}_{\text {mid }}$ in the hyperpolarizing direction by a mean of 4.4 $\mathrm{mV}$ (Figure 2B). Similarly, forskolin, which directly activates adenylyl cyclase, thereby bypassing $\beta$-adrenergic receptors, increased transgenic pWT $\alpha_{1 \mathrm{C}} \mathrm{Ca}^{2+}$ currents by 1.8-fold \pm 0.1-fold (Figure 2, $\mathrm{H}-\mathrm{J})$. In sharp contrast, $\mathrm{Ca}^{2+}$ currents through transgenic AID-mutant $\alpha_{1 \mathrm{C}} \mathrm{Ca}_{\mathrm{v}} 1.2$ channels were insensitive to either isoproterenol (Figure 2, B, F, G, I, and J) or forskolin (Figure 2, H-J). In cardiomyocytes, there is an inverse relationship between total peak current and isoproterenol-induced or forskolin-induced fold increase in $\mathrm{Ca}^{2+}$ current (27). In cardiomyocytes isolated from transgenic pWT $\alpha_{1 \mathrm{C}}$ mice, we observed an inverse relationship between basal current density and isoproterenol- or forskolin-induced increase in $\mathrm{Ca}^{2+}$ current (Figure 2J). For the transgenic AID-mutant $\beta$-less channels, however, activation of PKA by either forskolin or isoproterenol had no effect on $\mathrm{Ca}^{2+}$ current, regardless of basal $\mathrm{Ca}^{2+}$ current density (Figure 2J).

To address whether the YWI/AAA mutations themselves produced an intrinsic insensitivity of the channel to PKA modulation, we sought to engender conditions under which there would be a predominance of $\beta$-less endogenous $\mathrm{Ca}_{\mathrm{v}} 1.2$ channels in isolated cardiomyocytes. We achieved this by using adenovirus to overexpress a YFP-tagged 18-residue AID peptide derived from $\alpha_{1 \mathrm{C}}$ I-II loop (or a mutant YWI/AAA peptide as a control) in cultured adult guinea pig ventricular cardiomyocytes. We reasoned that this intervention would serve as a sponge for endogenous $\beta$ subunits, leaving a majority of endogenous $\mathrm{Ca}_{\mathrm{v}} 1.2$ channels devoid of $\beta$. In control cells expressing either GFP or YFP-tagged mutant (YWI/AAA) AID peptide incapable of binding $\beta, 1 \mu \mathrm{M}$ forskolin resulted in a robust 4- to 5 -fold increase in whole-cell current amplitude (Figure 3, A, C, D, and F-H). By contrast, this response was sharply curtailed in cardiomyocytes overexpressing YFP-AID peptide (Figure 3, B, E, G, and H). Hence, $\beta$-less WT $\alpha_{1 C}$ channels also demonstrate a marked insensitivity to PKA modulation.

We also considered 2 trivial explanations that could potentially account for the insensitivity of AID-mutant $\alpha_{1 C}$ to PKA stimulation: (a) these channels were already phosphorylated by PKA under basal conditions, or (b) the $\beta$-adrenergic signaling pathway was compromised in cardiomyocytes from AID-mutant $\alpha_{1 \mathrm{C}}$ transgenic mice. To address whether transgenic AID-mutant $\alpha_{1 C}$ channels were basally PKA phosphorylated, we used a cell-permeable cAMP-PKA inhibitor (Rp-8-Br-cAMPS), which functions by occupying cAMP binding sites thereby preventing activation of PKA holoenzyme. $\mathrm{Rp}-8$-Br-cAMPS reverses isoproterenol-mediated upregulation of endogenous $\mathrm{Ca}_{\mathrm{v}} 1.2$ by approximately $96 \%$ (23). In transgenic AID-mutant mice cardiomyocytes, Rp-8-Br-cAMPS did not inhibit nisoldipine-resistant basal current (Supplemental Figure $2 \mathrm{~A})$, ruling out the idea that AID-mutant $\alpha_{1 \mathrm{C}}$ channels were basally PKA phosphorylated. The integrity of the $\beta$-adrenergic pathway in transgenic AID-mutant mice cardiomyocytes was assessed by probing whether isoproterenol application led to phosphorylation of phospholamban, a well-known PKA target in the heart (35). Western blotting indicated that phospholamban was appropriately phosphorylated at $\operatorname{Ser}^{16}$ in response to isoproterenol (Supplemental Figure $2 \mathrm{~B}$ ), confirming that the $\beta$-adrenergic signaling pathway was intact in AID-mutant transgenic mice cardiomyocytes.

$\beta$-adrenergic regulation of $C a_{V} 1.2$ does not require PKA phosphorylation of $\beta$ subunits. The simplest explanation for the necessary role of $\alpha_{1 C}-\beta$ interaction in PKA modulation of $\mathrm{Ca}_{\mathrm{v}} 1.2$ is that the $\beta$-subunit contains phosphorylation site(s) that are vital to this regulation. Indeed, 2 phosphorylation sites on $\beta_{2} \mathrm{C}$-terminus $\left(\mathrm{Ser}^{512}\right.$ and $\left.\mathrm{Ser}^{570}\right)$ were previously identified and proposed to play a role in PKA modulation of $\mathrm{Ca}_{\mathrm{v}} 1.2$ (36). However, a knockin mouse expressing a $\beta_{2}$ subunit truncated after Pro ${ }^{501}$ displayed normal PKA modulation of $\mathrm{Ca}_{\mathrm{v}} 1.2$, thus ruling out involvement of any putative C-terminal phosphorylation sites (24). Nevertheless, it remained possible that previously unappreciated phosphorylation sites N-terminal to Pro ${ }^{501}$ could mediate the increased $\mathrm{Ca}_{\mathrm{v}} 1.2$ channel activity in response to activated PKA. Using both manual sequence analyses and several web-based PKA phosphorylation prediction tools (37-41), we identified 18 conserved consensus PKA phosphorylation sites in the N-terminus, $\mathrm{SH} 3$, and GK domains of human $\beta_{2 \mathrm{~b}}$ (residues labeled red in Supplemental Figure 3). We mutated all $18 \mathrm{Ser} / \mathrm{Thr}$ residues to Ala in human $\beta_{2 b}$, and generated transgenic mice with inducible cardiomyocyte-specific expression of either GFP-tagged WT or 18 -mutant $\beta_{2 b}$ subunits using the same bitransgenic system as in 


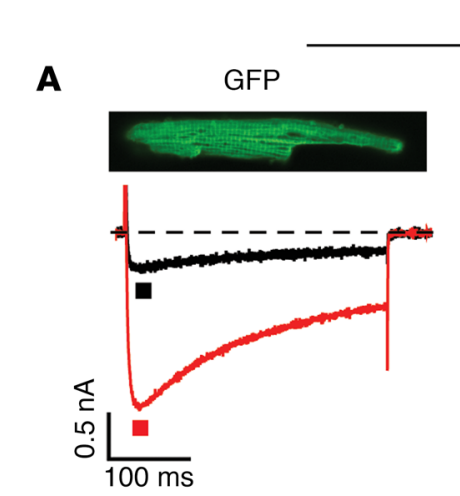

Adenoviral expression
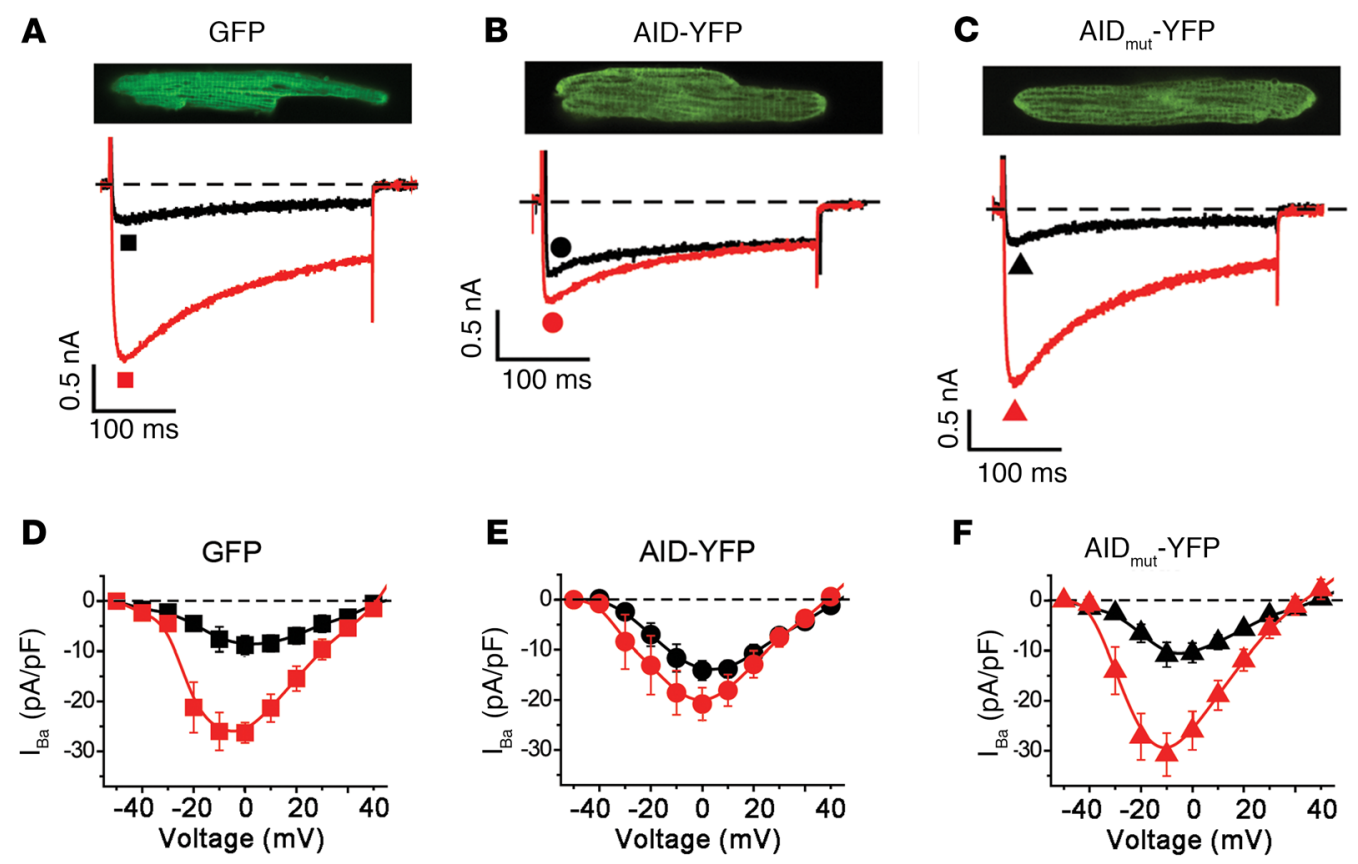

G

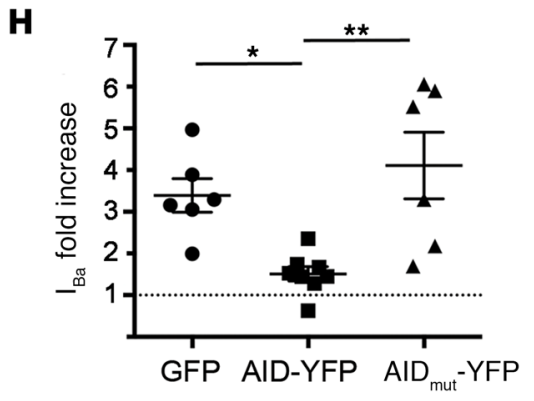

Figure 3. $\boldsymbol{\beta}$-less WT endogenous $\mathrm{Ca}_{\mathrm{v}} \mathbf{1 . 2}$ channels are not stimulated by PKA. (A-C) Adenovirus-induced GFP, AID-YFP, and AID-mutant YFP expression in cultured guinea pig ventricular myocytes. Top: exemplar confocal images from guinea pig cardiomyocytes expressing GFP, AID-YFP peptide, or AID-mutant YFP peptide. Bottom: exemplar whole-cell $\mathrm{Ba}^{2+}$ currents from GFP and YFP-expressing guinea pig ventricular cardiomyocytes before (black trace) and after (red trace) application of $1 \mu \mathrm{M}$ forskolin. (D-F) Current-voltage relationships from GFP, AID-YFP, and AID-mutant YFP-expressing cardiomyocytes before (black) and after (red) superfusion of $1 \mu \mathrm{M}$ forskolin. (G) Representative diary plot showing time course of forskolin-induced increase in Ca 1.2 current. (H) Forskolin-induced increase in $\mathrm{Ca}_{\mathrm{v}} 1.2$ current. ${ }^{*} P<0.05$, ${ }^{* *} P<0.01$ by 1 -way ANOVA and Tukey's multiple comparison test.

Figure $1 \mathrm{~B}$. The WT and mutant $\beta_{2 \mathrm{~b}}$ transgenic mice were fed doxycycline for 1 week, thus ensuring high levels of expression of the GFP-tagged $\beta_{2}$ subunits (Figure $4 \mathrm{~A}$ ). We exploited the larger size of GFP-tagged $\beta_{2}$ subunits compared with endogenous $\beta$ to determine relative expression of transgenic and native $\beta_{2}$ subunits (Figure 4B). Western blot indicated that in cardiomyocytes from transgenic mice, both GFP $\beta_{2}$ and GFP-mutant $\beta_{2}$ were markedly overexpressed $(\sim 9: 1)$ compared with endogenous $\beta_{2}$ (Figure $4 \mathrm{C}$ ). Isoproterenol increased peak $\mathrm{Ca}_{\mathrm{v}} 1.2$ current by a mean of 1.5 -fold \pm 0.1 -fold in GFP-WT $\beta_{2}$-expressing cells and 1.6 -fold \pm 0.1 -fold in GFP-mutant $\beta_{2}$-expressing cells, respectively, similar to nontransgenic mice (Figure 4, D-G). For both GFP-WT and GFP-mutant $\beta_{2 b} \mathrm{Ca}^{2+}$ channels, isoproterenol shifted the $V_{\text {mid }}$ of steady-state activation by $-7.0 \mathrm{mV}$ and $-7.5 \mathrm{mV}$, respectively. These data indicate that, although the $\alpha_{1 \mathrm{C}}-\beta_{2}$ interaction is necessary for $\beta$-adrenergic regulation of $\mathrm{Ca}_{\mathrm{v}} 1.2$, direct PKA phosphorylation of $\beta_{2}$ is not involved. $\beta$-adrenergic regulation of cardiac contractility requires $P K A$ regulation of $C a_{V}$ 1.2. We next exploited the findings that transgenic $\beta$-less AID-mutant $\alpha_{1 \mathrm{C}}$ channels are insensitive to PKA modulation to probe the specific role of $\mathrm{Ca}_{\mathrm{v}} 1.2$ modulation in the positive inotropic effect of $\beta$-adrenergic agonists in both isolated cardiomyocytes and in the whole heart. In transgenic $\mathrm{pWT} \alpha_{1 \mathrm{C}}$ cardiomyocytes, with endogenous $\mathrm{Ca}_{\mathrm{v}} 1.2$ channels silenced with nisoldipine, isoproterenol produced a robust 100\% increase in fractional shortening (Figure 5, A and C). By contrast, this response was severely diminished in cardiomyocytes expressing transgenic $\beta$-less AID-mutant $\alpha_{1 \mathrm{C}}$ channels in which isoproterenol produced a relatively meager $25 \%$ increase in fractional shortening (Figure 5, B and C). Consistent with the effects of isoproterenol on phospholamban phosphorylation (Supplemental Figure 2B), isoproterenol enhanced relaxation in cardiomyocytes isolated from both pWT and AID-mutant $\alpha_{1 C}$ transgenic mice (Figure 5D).

We then assessed the role of $\mathrm{Ca}_{\mathrm{v}} 1.2$ modulation in $\beta$-adrenergic agonist-induced positive inotropy at the whole-organ level 
A

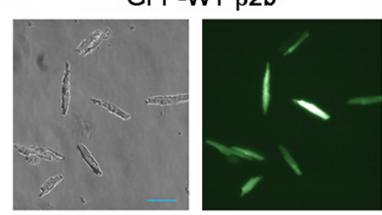

GFP-Mutant $\beta 2 b$

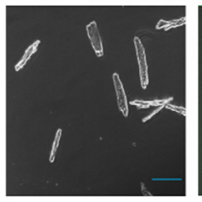

B

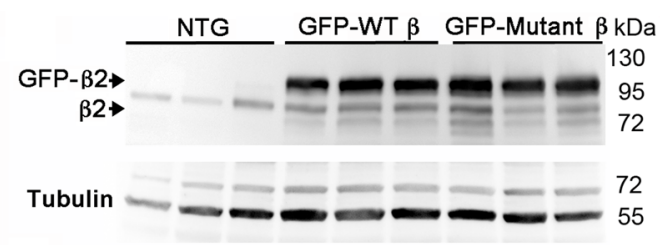

C

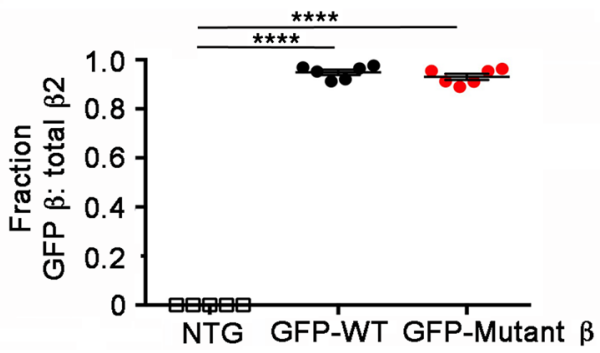

D

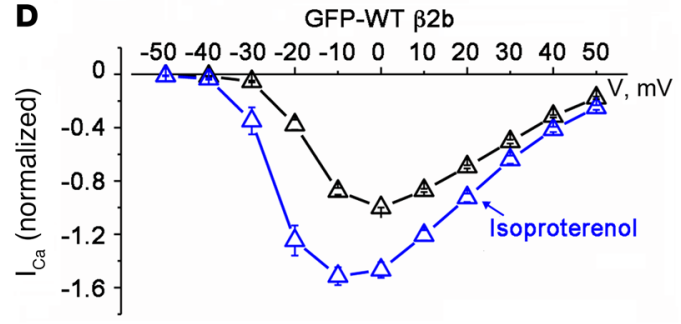

$\mathbf{F}$

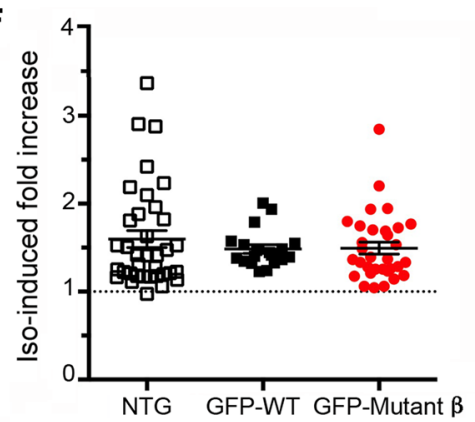

E

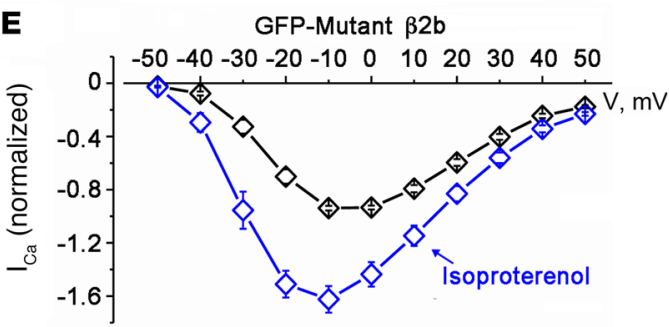

G

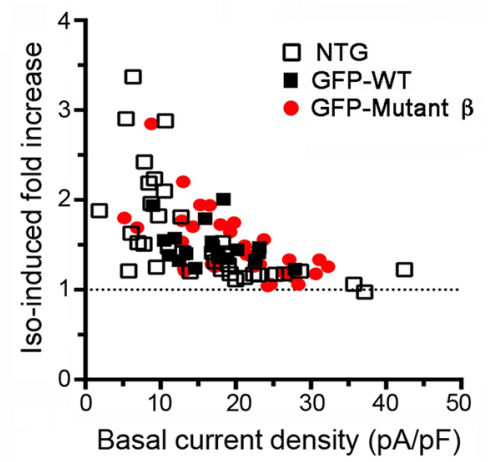

Figure 4. PKA phosphorylation of $\mathrm{Ca}_{\mathrm{v}} \boldsymbol{\beta}$ is not required for $\boldsymbol{\beta}$-adrenergic regulation of $\mathrm{Ca}_{\mathrm{v}}$ 1.2. (A) Bright-field and $\mathrm{CFP}$ image of WT and mutant $\beta_{2 \mathrm{~b}}$-expressing cardiomyocytes. Scale bars: $100 \mu \mathrm{m}$. (B) Immunoblots using anti- $\beta_{2}$ antibody (upper) and anti-tubulin antibody of homogenates from the hearts of nontransgenic (NTG) and doxycycline-fed GFP-WT $\beta_{2}$ and GFP-mutant $\beta_{2}$-expressing mice. (C) Graph of densitometry of fraction of GFP- $\beta /$ total $\beta$. Mean \pm SEM; $n=6$ mice for NTG, WT, and mutant $\beta_{2}{ }^{* * * *} P<0.0001$ compared with nontransgenic by 1-way ANOVA and Dunnett's multiple comparison test. (D and E) Normalized current-voltage relationships of GFP-WT $\beta_{2}$ and GFP-mutant $\beta_{2}$ cardiomyocytes acquired before and after superfusion of $200 \mathrm{nM}$ isoproterenol. Isoproterenol shifted the $V_{\text {mid }}$ of steady-state activation of GFP-WT $\beta_{2}$ and GFP-mutant $\beta_{2}$ cardiomyocytes by $-7.0 \mathrm{mV}(P<0.0001, t$ test, $n=15)$ and $-7.5 \mathrm{mV}(P<0.001, t$ test, $n=30)$, respectively. (F) Column scatter plot depicting the fold increase in peak current caused by isoproterenol. Mean \pm SEM; $n=36$ cardiomyocytes from 5 NTC mice; $n=$ 19 cardiomyocytes from 4 GFP-WT $\beta_{2 b}$ mice; $n=32$ cardiomyocytes from 5 mutant $\beta_{2 b}$ mice. $P=0.55$ by 1 -way ANOVA. (G) Graphs of isoproterenol-induced increase in current stratified by total basal current density for cardiomyocytes isolated from NTC mice, GFP-WT $\beta_{2 b}$ mice, and GFP-mutant $\beta_{2 b}$ transgenic mice.

by inserting a pressure-transduced balloon into the left ventricle of Langendorff-perfused transgenic mice hearts. This approach enabled measurement of cardiac contractility independent of vascular or systemic effects. Hearts were paced at 400 beats per minute to remove the potentially confounding effect of heart rate variability on contractility (42). After baseline measurements, $300 \mathrm{nM}$ nisoldipine was infused into the coronary arteries via the aorta to suppress endogenous $\mathrm{Ca}_{\mathrm{v}} 1.2$ channel currents. In hearts from nontransgenic mice, nisoldipine markedly reduced basal cardiac contractility due to the block of endogenous $\mathrm{Ca}_{\mathrm{v}} 1.2$ channels (Figure $5 \mathrm{E}$ ). In $\mathrm{pWT} \alpha_{1 \mathrm{C}}$ hearts, infusion of nisoldipine yielded a comparatively weaker effect on basal con- tractility owing to the expression of DHP-resistant $\mathrm{Ca}^{2+}$ channels (Figure 5F); a further infusion of $200 \mathrm{nM}$ isoproterenol strongly increased cardiac contractility by 3.3-fold (Figure 5, G and I). By contrast, using the same experimental paradigm in hearts from $\beta$-less AID-mutant transgenic mice, the response to isoproterenol was nearly abolished, yielding an average increase in cardiac contractility of only 1.2-fold (Figure 5, H and I).

\section{Discussion}

Much of our current understanding regarding mechanisms underlying $\mathrm{Ca}_{\mathrm{v}} 1.2$ trafficking and modulation derives from studies on recombinant channels reconstituted in heterologous cells. These 
A

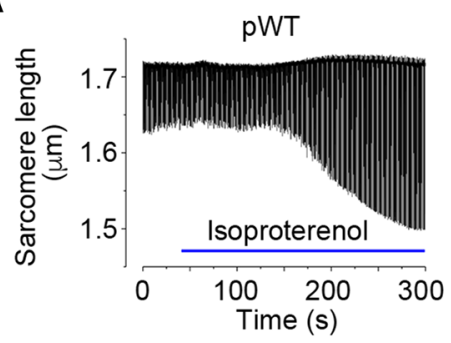

D

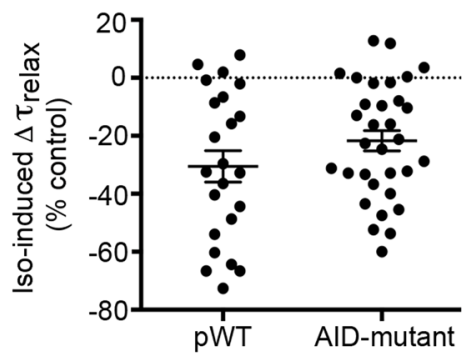

$\mathbf{F}$

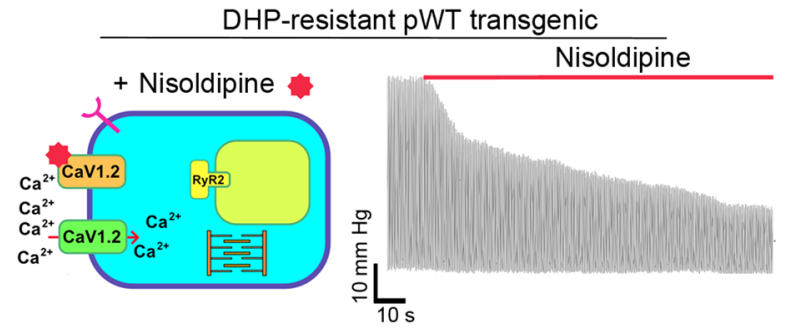

H

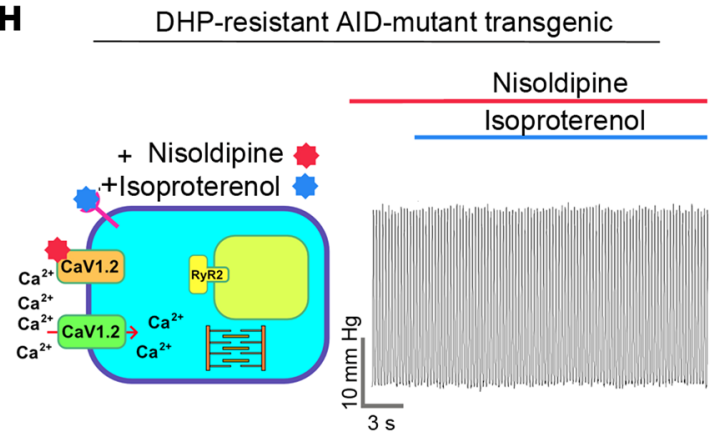

B

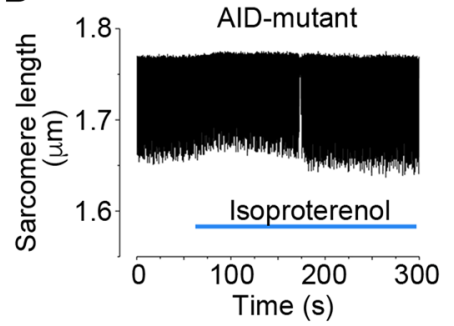

E

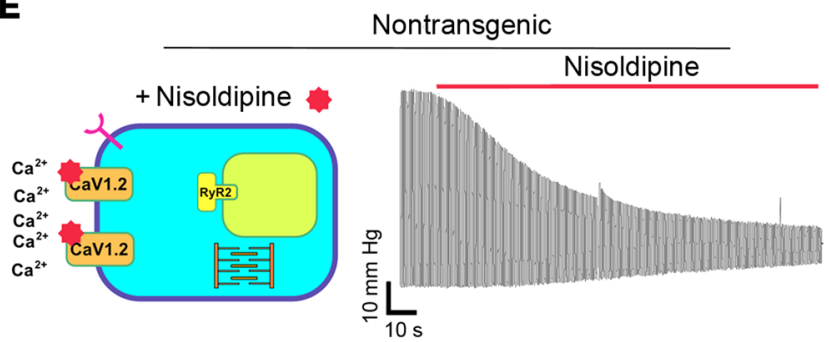

G

DHP-resistant pWT transgenic

c

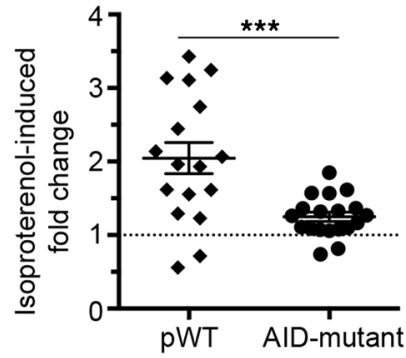

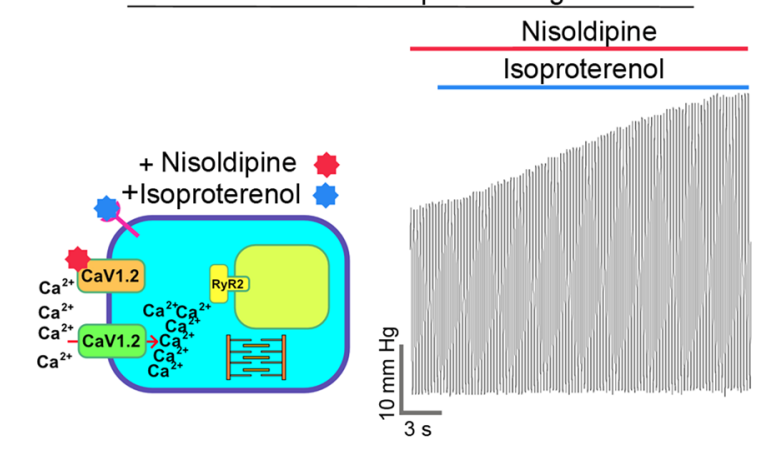

I

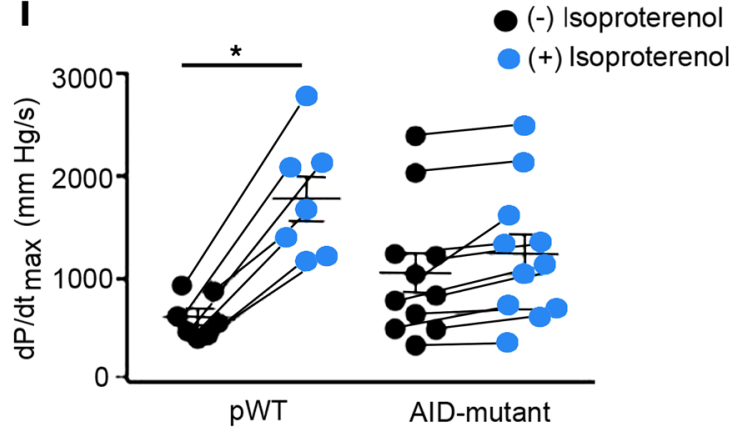

Figure 5. Attenuated $\beta$-adrenergic-stimulated inotropy in AID-mutant $\boldsymbol{\alpha}_{1 \mathrm{c}}$ transgenic mice. (A and B) Cells with robust shortening induced by $1 \mathrm{~Hz}$ electrical stimulation in the presence of $300 \mathrm{nM}$ nisoldipine were used. Isoproterenol ( $200 \mathrm{nM}$ ) was superfused with $300 \mathrm{nM}$ nisoldipine. (C) Plot of isoproterenol-induced fold change in sarcomere length compared with before isoproterenol. Mean \pm SEM; $n=17$ for pWT $\alpha_{1 C}$ cardiomyocytes and $n=19$ cardiomyocytes for AID-mutant $\alpha_{1 c^{\circ}}{ }^{* *} P<0.001$ by $t$ test. (D) Plot of isoproterenol-induced percentage of change in $\tau_{\text {relaxation }}$ of sarcomere length compared with before isoproterenol. Mean \pm SEM; $n=23$ cardiomyocytes from 3 mice and $n=32$ cardiomyocytes from 3 mice. $P=0.16$ by $t$ test. (E and $\mathbf{F}$ ) Representative traces depicted effect of perfusion of $300 \mathrm{nM}$ nisoldipine on left ventricular contraction in isolated Langendorff-perfused hearts resected from NTC mice and pWT $\alpha_{11}$ transgenic mice. (G and $\mathbf{H}$ ) Representative traces of nisoldipine-resistant LV pressure before and during isoproterenol infusion, in hearts resected from pWT $\alpha_{1 C}$ and AID-mutant $\alpha_{1 c}$ transgenic mice. (I) Quantitative summary of $d P / d t_{\max }$ before and during isoproterenol infusion. $n=7 \mathrm{pWT} \alpha_{1 c}$ transgenic mice; $n=11$ AID-mutant $\alpha_{1 C}$ transgenic mice. ${ }^{*} P<0.05$ by $t$ test.

cells lack the complex cytoarchitecture and intracellular milieu of adult cardiomyocytes. Recently, we developed an approach that utilizes transgenic mice expressing doxycycline-inducible, cardiac-specific, DHP-resistant $\alpha_{1 \mathrm{c}}$. Compared with knockin mice models $(43,44)$, this approach is both cost-effective and rapid, and perhaps more importantly, enables us to induce brief expression of mutant channels in adults, permitting the comparison of WT and mutant $\alpha_{1 \mathrm{C}}$ structure-function mechanisms in the absence of developmental abnormalities and heart failure. The titration of the level of $\mathrm{Ca}_{\mathrm{v}} 1.2$ expression is important, as the magnitude of $\beta$-adrener- 
gic stimulation of $\mathrm{Ca}_{\mathrm{v}} 1.2$ is reduced with increased basal current density (27, 45-49). Stratifying the magnitude of $\beta$-adrenergicmediated upregulation of $\mathrm{Ca}_{\mathrm{v}} 1.2$ current by total basal current density attenuates this confounding variable (Figure 2J and Figure $4 G$ ).

Overall, we show that in cardiomyocytes, the AID motif is required for the high-affinity interaction between $\alpha_{1 C}$ and $\beta$ subunits, and that $\beta$-less $\mathrm{Ca}_{\mathrm{v}} 1.2$ channels traffic to the dyad and produce currents that mediate normal E-C coupling. The AID-mutant $\beta$-less $\mathrm{Ca}^{2+}$ currents were completely refractory to PKA activation. These findings, combined with our recent studies (23), fundamentally recast our views on mechanisms underlying $\mathrm{Ca}_{\mathrm{v}} 1.2$ trafficking and PKA modulation in cardiomyocytes as they show that (a) it is possible for $\beta$-less channels to traffic to the cell surface, (b) $\beta_{2}$ binding to $\alpha_{1 \mathrm{C}}$ is indispensable for PKA modulation of $\mathrm{Ca}_{\mathrm{v}} 1.2$, and that $\beta$-adrenergic regulation of $\mathrm{Ca}_{\mathrm{v}} 1.2$ can be specifically attenuated by sequestering $\beta$ subunits, and (c) conserved consensus PKA phosphorylation sites in $\alpha_{1 C}$ (23) and $\beta_{2 \mathrm{~b}}$ are not required for $\beta$-adrenergic regulation of $\mathrm{Ca}_{\mathrm{v}} 1.2$ in the heart. Further, we directly show that $\beta$-adrenergic modulation of $\mathrm{Ca}_{\mathrm{v}} 1.2$ is critical for sympathetic augmentation of cardiac inotropy, which is essential for the fight-or-flight response.

When coexpressed with $\alpha_{1}$ subunits in heterologous expression systems such as Xenopus oocytes or human embryonic kidney (HEK) cells, $\beta$ subunits markedly augment current density by increasing membrane targeting and altering electrophysiological properties (6-8). In the adult heart, however, $\mathrm{Ca}^{2+}$ channels can traffic to the surface membrane without binding to $\beta$. How $\beta$-less $\alpha_{1 \mathrm{C}}$ channels traffic to the dyad in cardiomyocytes but not in a less complex system such as HEK cells is not yet clear. Although low-affinity interactions between heterologously expressed $\beta$ subunit GK and SH3 domains and the $\mathrm{Ca}_{\mathrm{v}} 2.1 \alpha$ subunit in oocytes have been described (50), these potential interactions do not appear to be sufficient to rescue the trafficking of AID-mutant $\mathrm{Ca}_{\mathrm{v}} 1.2$ channels in tsA-201 cells. Moreover, conditional knockout of Cacnb2 in adult cardiomyocytes caused only a 29\% reduction in current density (19).

Regardless of the mechanisms enabling trafficking to the cell surface, $\beta$-less $\mathrm{Ca}_{\mathrm{v}} 1.2$ channels are functionally normal under basal conditions in adult cardiomyocytes. However, the $\beta$-less channels cannot be regulated by adrenergic-PKA stimulation, although the $\beta$ subunit does not appear to be the functional target of PKA. To differentiate between the lack of $\beta$ binding as opposed to the mutations in the AID as causative of the defect in $\beta$-adrenergic regulation of $\mathrm{Ca}_{\mathrm{v}} 1.2$, we used the complementary approach of expressing using adenovirus, YFP-AID- and YFP-mutant AID-containing peptides in cultured adult guinea pig ventricular myocytes. The response to forskolin was markedly reduced by preventing $\beta$ subunits from interacting with endogenous $\mathrm{WT} \alpha_{1 \mathrm{C}}$, implying that lack of $\beta$ binding to $\alpha_{1 \mathrm{C}}$ is sufficient to prevent $\beta$-adrenergic regulation of $\mathrm{Ca}_{\mathrm{v}} 1.2$ in the heart. Our studies cannot address where and when $\beta$ subunits first interact with $\alpha_{1 \mathrm{C}}$ subunits in the heart.

Identifying the functional PKA target is more complicated. It is likely not solely $\alpha_{1 \mathrm{C}}$, based on our prior studies eliminating all conserved consensus PKA phosphorylation sites in the $\alpha_{1 \mathrm{C}}$ subunit (23). Likewise, it is not solely $\beta$, based on eliminating all conserved PKA phosphorylation sites in $\beta_{2}$ (Figure 4 ). Thus, our findings suggest that either there is redundancy between $\alpha_{1 \mathrm{C}}$ and $\beta$ subunits, such that PKA phosphorylation of either subunit is sufficient to mediate adrenergic regulation of $\mathrm{Ca}^{2+}$ channels in the heart, or that PKA phosphorylation of the core $\mathrm{Ca}_{\mathrm{v}} 1.2$ subunits, $\alpha_{1 \mathrm{C}}$ and $\beta$, are not necessary for $\beta$-adrenergic regulation of the $\mathrm{Ca}^{2+}$ influx in the heart. This can be addressed by cross-breeding the transgenic mice harboring Ala substitutions of all PKA consensus sites in $\alpha_{1 \mathrm{C}}$ and $\beta_{2 \mathrm{~b}}$. Although PKA phosphorylation of $\beta$ is not required, $\beta$ subunits, via binding to the I-II loop, could regulate pore opening and voltage-sensor movement. The domain I S6-AID linker forms a continuous helix that may act as a rigid rod through which $\beta$ subunits modulate channel gating (51).

The loss of $\beta$-adrenergic activation of $\mathrm{Ca}_{\mathrm{v}} 1.2$ correlated with a markedly attenuated $\beta$-adrenergic contractile response. Originally proposed by Fabiato, $\mathrm{Ca}_{\mathrm{v}} 1.2$ current has 2 distinct roles in $\mathrm{E}-\mathrm{C}$ coupling: triggering the release of $\mathrm{Ca}^{2+}$ from the sarcoplasmic reticulum (SR) and loading the cell (and SR) with $\mathrm{Ca}^{2+}(52)$. The loss of adrenergic regulation of $\mathrm{Ca}_{\mathrm{v}} 1.2$ could affect both triggering of RyR2 and the loading of SR with $\mathrm{Ca}^{2+}$, thereby attenuating the adrenergically driven inotropic response. We believe that our findings are the first to demonstrate experimentally the vital role of $\beta$-adrenergic stimulation of $\mathrm{Ca}_{\mathrm{v}} 1.2$ in shaping the flight-or-fight response in the heart, and validate a recently proposed mathematical model predicting that the loss of $\beta$-adrenergic stimulation of $\mathrm{Ca}_{\mathrm{v}} 1.2$ would markedly limit $\mathrm{Ca}^{2+}$ transients and contraction (53). PKA and $\mathrm{Ca}^{2+} /$ calmodulin-dependent protein kinase II (CaMKII) phosphorylation of RyR2 also enhances the open probability of the RyR2 $\mathrm{Ca}^{2+}$ release channels in the SR by enhancing their sensitivity to cytosolic (54) and synchronizing SR $\mathrm{Ca}^{2+}$ release (55-57). It remains controversial, however, as to whether increasing the open probability of RyR2 is critically important for inotropic responses in the heart (58-60). We demonstrate that without augmented $\mathrm{Ca}_{\mathrm{v}} 1.2$ current to load the cell with additional $\mathrm{Ca}^{2+}$ and/or enhance RyR opening via $\mathrm{Ca}^{2+}$-induced $\mathrm{Ca}^{2+}$ release, $\beta$-adrenergic agonist-induced phosphorylation of RyR2 and phospholamban does not result in substantial $\beta$-adrenergic augmentation of cardiac contractility.

In summary, we have found that $\mathrm{Ca}^{2+}$ channel $\beta$-subunit binding to the pore-forming $\alpha_{1 C}$ subunit is not required for trafficking and function of the $\mathrm{Ca}^{2+}$ channel in the heart. The loss of $\alpha_{1 \mathrm{C}}-\beta_{2}$ binding causes marked attenuation of $\beta$-adrenergic-induced stimulation of $\mathrm{Ca}_{\mathrm{v}} 1.2$ and inotropy. Thus, we identify a new function for $\beta$ subunits in the heart: as an essential component of the PKA-mediated augmentation of $\mathrm{Ca}_{\mathrm{v}} 1.2$ and increased cardiac contractility that occurs during the physiological fight-or-flight response.

\section{Methods}

Reagents. Nisoldipine and Rp-8-Br-cAMPS were purchased from Santa Cruz Biotechnology. All other chemicals were acquired from MilliporeSigma.

Animals. The $\alpha_{1 \mathrm{C}}$ transgenic constructs were generated by fusing rabbit Cacna1c cDNA (accession X15539) to the modified murine $\alpha$-myosin heavy chain (MHC) tetracycline-inducible promoter ("responder" line) vector (gift of Jeffrey Robbins and Jeffrey Molkentin, University of Cincinnati, Cincinnati, OH) $(61,62)$. The $\alpha_{1 \mathrm{C}}$ subunit was engineered to be both DHP insensitive with the substitutions T1066Y and Q1070M $(32,33)$ and tagged with a 3X-FLAG epitope. We made alanine substitutions of 3 conserved residues, Y467, W470, and I471, in the AID domain of rabbit $\alpha_{1 \mathrm{C}}$ (Figure 1A). Two distinct 
AID-mutant $\alpha_{1 \mathrm{C}}$ were created and studied. The results obtained from each of these lines were equivalent and therefore the data were pooled. The $\beta_{2 \mathrm{~b}}$ transgenic constructs were generated by ligating a N-terminal GFP-tagged human CACNB2b cDNA (accession AAG01473) to the tetracycline-inducible vector. These mice were bred with cardiac-specific $(\alpha \mathrm{MHC})$, doxycycline-regulated, codon-optimized reverse transcriptional transactivator (rtTA) mice (obtained via the Mutant Mouse Resource and Research Center [MMRRC]) (63) to generate double-transgenic mice. The $\alpha_{1 \mathrm{C}}$ transgenic animals received $0.2 \mathrm{~g} / \mathrm{kg}$ doxycycline-impregnated food (Bio Serv catalog S3888) for 1-2 days and the GFP- $\beta_{2 b}$ transgenic mice received the doxycycline-impregnated food for 1 week to maximize expression.

Generation of adenoviral vectors and infection of guinea pig ventricular cardiomyocytes. Replication-deficient adenoviral vectors expressing AID-YFP and AID-mutant YFP were generated using the AdEasy Adenoviral Vector System (Agilent Technologies) according to the manufacturer's instructions. Briefly, sequences for AID-YFP and AID-mutant YFP were PCR-amplified and cloned into pShuttle-CMV vector. After linearization with PmeI, shuttle vectors were electroporated into BJ5183 cells containing pAdEasy-1 viral plasmid. Positive recombinants were amplified, linearized with Pac I, and transfected into AD-293 cells using the calcium phosphate precipitation method. Transfected cells were monitored for development of adenoviral plaques, after which the cells were freeze-thawed and the lysate used to infect a $10-\mathrm{cm}$ dish of $90 \%$ confluent HEK293 cells. Viral expansion and purification were carried out as previously described (64).

Adult guinea pig ventricular myocytes were isolated by enzymatic digestion using a Langendorff perfusion apparatus, and cultured as previously described (27). Animal treatment and use were in accordance with a protocol approved by the Columbia University Institutional Animal Care and Use Committee. Heart cells were infected 2-3 hours after plating with $5-20 \mu$ adenoviral vector stock $\left(\approx 10^{11}-10^{12}\right.$ viral particles $/ \mathrm{ml})$.

Immunoprecipitation, immunoblots, and immunofluorescence. Cardiac lysates from 6- to 12-week-old doxycycline-fed transgenic mice were prepared from either whole hearts or isolated ventricular cardiomyocytes (65). Immunoprecipitations were performed in modified RIPA buffer consisting of $50 \mathrm{mM}$ Tris $\mathrm{HCl}$; $\mathrm{pH} 7.4,150 \mathrm{mM} \mathrm{NaCl}$, Triton X-100 (0.25\%), 10 mM EDTA, 10 mM EGTA, $10 \mu \mathrm{M}$ Calpain inhibitor I, $10 \mu \mathrm{M}$ Calpain inhibitor II, and Complete Mini tablets (1 per $7 \mathrm{ml}$ ), using anti-FLAG antibody (MilliporeSigma) overnight. Immune complexes were collected using protein A (Amersham) for 2 hours, followed by extensive washing. Proteins were size-fractionated, transferred to nitrocellulose membranes, and probed with anti-FLAG antibody (MilliporeSigma), anti-tubulin antibody (Santa Cruz Biotechnology), and custom anti- $\alpha_{1 C}$ and anti- $\beta_{2}$ antibodies (65). Detection was performed with a charge-coupled device camera (Carestream Imaging), and ImageQuant software was used for quantification. Isolated cardiomyocytes were fixed for 15 minutes in $4 \%$ paraformaldehyde, and indirect immunofluorescence was performed using a 1:200 rabbit anti-FLAG antibody and 1:200 FITC-labeled goat-anti-rabbit antibody (MilliporeSigma). Images were acquired using a confocal microscope.

Cellular electrophysiology. Membrane currents from isolated mouse ventricular cardiomyocytes (66) were measured by the wholecell patch-clamp method using a MultiClamp 700B amplifier and pCLAMP 10 software (Molecular Devices) as described (65). The pipette solution contained $40 \mathrm{mM} \mathrm{CsCI}, 90 \mathrm{mM}$ Cs gluconate, 10 mM BAPTA, $1 \mathrm{mM} \mathrm{MgCl}$, $4 \mathrm{mM} \mathrm{Mg-ATP,} 2 \mathrm{mM} \mathrm{CaCl}_{2}$, and $10 \mathrm{mM}$ HEPES, adjusted to $\mathrm{pH} 7.2$ with $\mathrm{CsOH}$. After the isolated cardiomyocytes were adequately buffered with $10 \mathrm{mM}$ BAPTA in the internal solution, the isolated cardiomyocytes were superfused with $140 \mathrm{mM}$ TEA-Cl, $1.8 \mathrm{mM} \mathrm{CaCl}_{2}, 1 \mathrm{mM} \mathrm{MgCl}, 10 \mathrm{mM}$ glucose, and $10 \mathrm{mM}$ HEPES, adjusted to pH 7.4 with CsOH. For experiments in tsA-201 cells, TEA-Cl was reduced to $130 \mathrm{mM}$, and $10 \mathrm{mM} \mathrm{BaCl}_{2}$ was used instead of $\mathrm{CaCl}_{2}$. Pipette series resistances were usually less than $1 \mathrm{M} \Omega$ after $60 \%$ compensation. Leak currents and capacitance transients were subtracted by a $\mathrm{P} / 4$ protocol. Voltages were corrected for the liquid junction potential of $-10 \mathrm{mV}$. To measure $\mathrm{Ca}^{2+}$ peak currents, the cell membrane potential was held at $-50 \mathrm{mV}$ and stepped to $+10 \mathrm{mV}$ for 350 ms every 10 seconds. To evaluate the I-V relationship for $\mathrm{Ca}^{2+}$ currents, the same protocol was repeated with steps between $-50 \mathrm{mV}$ to $+50 \mathrm{mV}$ in $10-\mathrm{mV}$ increments. All experiments were performed at room temperature, $22^{\circ} \mathrm{C} \pm 1^{\circ} \mathrm{C}$. The parameters of voltage-dependent activation were obtained using a modified Boltzmann distribution: $\left.\mathrm{I}(\mathrm{V})=\mathrm{G}_{\text {max }} *\left(\mathrm{~V}-\mathrm{E}_{\text {rev }}\right) /\left[1+\exp \left(\mathrm{V}_{\text {mid }}-\mathrm{V}\right) / \mathrm{V}_{\mathrm{c}}\right)\right]$, where $\mathrm{I}(\mathrm{V})$ is peak current, $G_{\text {max }}$ is maximal conductance, $E_{\text {rev }}$ is reversal potential, $V_{\text {mid }}$ is the midpoint, and $\mathrm{V}_{\mathrm{c}}$ is the slope factor.

Whole-cell recordings of virally infected cultured guinea pig ventricular myocytes were conducted at room temperature as previously described $(27,67)$. Patch pipettes typically had 1-2 M $\Omega$ series resistance when filled with internal solution containing $150 \mathrm{mM}$ cesium-methanesulfonate, $10 \mathrm{mM}$ EGTA, $5 \mathrm{mM} \mathrm{CsCl}, 1 \mathrm{mM} \mathrm{MgCl}_{2}, 10$ $\mathrm{mM}$ HEPES, and $4 \mathrm{mM}$ MgATP (pH 7.3). Cells were perfused with normal Tyrode external solution during formation of gigaohm seal. After successful break-in to the whole-cell configuration, the perfusing medium was switched to an external recording solution containing $155 \mathrm{mM} \mathrm{N}$-methyl-D-glucamine-aspartate, $10 \mathrm{mM}$ 4-aminopyridine, $1 \mathrm{mM} \mathrm{MgCl}, 5 \mathrm{mM} \mathrm{BaCl}_{2}$, and $10 \mathrm{mM}$ HEPES (pH 7.4). Currents were sampled at $50 \mathrm{KHz}$ and filtered at $5 \mathrm{KHz}$, and leak and capacitive currents were subtracted using a $\mathrm{P} / 8$ protocol.

Fractional shortening of isolated cardiomyocytes. Freshly isolated myocytes were superfused with a Tyrode's solution containing 1.0 $\mathrm{mM} \mathrm{CaCl}_{2}$ and $300 \mathrm{nM}$ nisoldipine. Myocytes were field stimulated at $1 \mathrm{~Hz}$. Percent contraction of sarcomere length was measured using the SarcLen module (Ionoptix) and calculated as the difference of shortest sarcomere length during a contraction subtracted from the relaxed sarcomere length, divided by the relaxed sarcomere length, all averaged over at least 8 contractions.

Ex vivo cardiac contractility. The cannulated hearts were retrogradely perfused on a Langendorff system with a modified Krebs solution $(118.5 \mathrm{mM} \mathrm{NaCl}, 25 \mathrm{mM} \mathrm{NaHCO}, 4.7 \mathrm{mM} \mathrm{KCl}, 1.2 \mathrm{mM}$ $\mathrm{MgSO}_{4}, 1.2 \mathrm{mM} \mathrm{KH}_{2} \mathrm{PO}_{4}, 11 \mathrm{mM}$ glucose, $\left.1.8 \mathrm{mM} \mathrm{Ca}^{2+}\right)$. Left ventricular (LV) pressure was measured using a balloon catheter connected to an APT-300 pressure transducer, which was connected to a PowerLab digitizer (ADInstruments). Hearts were paced at 400 beats per minute using electrodes connected to a pacing stimulator system. After initial assessment of cardiac contractility, $300 \mathrm{nM}$ nisoldipine was perfused to silence endogenous $\mathrm{Ca}^{2+}$ currents. The effects of nisoldipine on contractility were assessed after at least 3 minutes and on stabilization of $\mathrm{LV}$ pressures. Thereafter, $200 \mathrm{nM}$ isoproterenol was perfused with $300 \mathrm{nM}$ nisoldipine for at least 3 minutes. Peak LV pressure during the 3-minute period was used for the assessment of $\beta$-adrenergic agonist stimulation. 
Statistics. Results are mean \pm SEM. For multiple group comparisons, 1-way ANOVA followed by multiple comparison testing was performed. For comparisons between 2 groups, an unpaired Student's $t$ test was used. Statistical analyses were performed using Prism 6 (Graphpad Software). Differences were considered statistically significant at $P$ values less than 0.05 .

Data availability. The data and study materials will be made available to other researchers for purposes of reproducing the results or replicating the procedure.

Study approval. The Institutional Animal Care and Use Committee at Columbia University approved all animal experiments.

\section{Author contributions}

SOM, HMC, and GSP conceived the study. LY, A Katchman, JK, A Kushnir, SIZ, SV, SOM, HMC, and GSP determined the study methodology. LY, A Katchman, JK, A Kushnir, SIZ, BC, ZS, PS, GL, AP, DR,
SOM, and HMC carried out the study investigation. SOM, HMC, and GSP wrote the original draft of the manuscript. LY, A Katchman, JK, A Kushnir, SIZ, BC, SV, GL, AP, DR, GSP, HMC, and SOM reviewed and edited the manuscript. SOM, HMC, and GSP acquired funding for the study. SOM, HMC, and GSP contributed resources to the study.

\section{Acknowledgments}

This work was supported by NIH grants R01 HL113136, R01 HL121253, HL126735, and HL 140934. JK was supported by NIH grant T32 HL007343. ZS, AP, and DR were supported by NIH grant T32HL120826.

Address correspondence to: Steven Marx, Columbia University, Vagelos College of Physicians and Surgeons, 622 W. 168th Street, PH-3 Center, New York, New York 10032, USA. Phone: 212.305.0271; Email:sm460@cumc.columbia.edu.
1. Catterall WA. Structure and regulation of voltage-gated Ca2+ channels. Annu Rev Cell Dev Biol. 2000;16:521-555.

2. Min D, et al. The alterations of $\mathrm{Ca} 2+/$ calmodulin/ CaMKII/CaV1.2 signaling in experimental models of Alzheimer's disease and vascular dementia. Neurosci Lett. 2013;538:60-65.

3. Peterson BZ, DeMaria CD, Adelman JP, Yue DT. Calmodulin is the $\mathrm{Ca} 2+$ sensor for $\mathrm{Ca} 2+$-dependent inactivation of L-type calcium channels. Neuron. 1999;22(3):549-558.

4. Erickson MG, Alseikhan BA, Peterson BZ, Yue DT. Preassociation of calmodulin with voltage-gated $\mathrm{Ca}(2+)$ channels revealed by FRET in single living cells. Neuron. 2001;31(6):973-985.

5. Scriven DR, Dan P, Moore ED. Distribution of proteins implicated in excitation-contraction coupling in rat ventricular myocytes. Biophys J. 2000;79(5):2682-2691.

6. Perez-Reyes E, et al. Cloning and expression of a cardiac/brain beta subunit of the L-type calcium channel. J Biol Chem. 1992;267(3):1792-1797.

7. Castellano A, Wei X, Birnbaumer L, PerezReyes E. Cloning and expression of a neuronal calcium channel beta subunit. J Biol Chem. 1993;268(17):12359-12366.

8. Lacerda AE, et al. Normalization of current kinetics by interaction between the alpha 1 and beta subunits of the skeletal muscle dihydropyridine-sensitive $\mathrm{Ca} 2+$ channel. Nature. 1991;352(6335):527-530.

9. Bichet D, et al. The I-II loop of the $\mathrm{Ca} 2+$ channel alpha1 subunit contains an endoplasmic reticulum retention signal antagonized by the beta subunit. Neuron. 2000;25(1):177-190.

10. Chien AJ, et al. Roles of a membrane-localized beta subunit in the formation and targeting of functional L-type Ca2+ channels. J Biol Chem. 1995;270(50):30036-30044.

11. Brice NL, et al. Importance of the different beta subunits in the membrane expression of the alpha1A and alpha 2 calcium channel subunits: studies using a depolarization-sensitive alpha1A antibody. Eur J Neurosci. 1997;9(4):749-759.

12. Dolphin AC. Beta subunits of voltage-gated calcium channels. J Bioenerg Biomembr. 2003;35(6):599-620.
13. Buraei Z, Yang J. The $ß$ subunit of voltage-gated Ca2+ channels. Physiol Rev. 2010;90(4):1461-1506.

14. Arikkath J, Campbell KP. Auxiliary subunits: essential components of the voltage-gated calcium channel complex. Curr Opin Neurobiol. 2003;13(3):298-307.

15. Weissgerber $P$, et al. Reduced cardiac L-type $\mathrm{Ca} 2+$ current in $\mathrm{Ca}(\mathrm{V})$ beta2-/- embryos impairs cardiac development and contraction with secondary defects in vascular maturation. Circ Res. 2006;99(7):749-757.

16. Altier C, et al. The Cav $\beta$ subunit prevents RFP2-mediated ubiquitination and proteasomal degradation of L-type channels. Nat Neurosci. 2011;14(2):173-180.

17. Fang K, Colecraft HM. Mechanism of auxiliary $\beta$-subunit-mediated membrane targeting of L-type (Ca(V)1.2) channels. J Physiol (Lond). 2011;589(Pt 18):4437-4455.

18. Waithe D, Ferron L, Page KM, Chaggar K, Dolphin AC. Beta-subunits promote the expression of $\mathrm{Ca}(\mathrm{V}) 2.2$ channels by reducing their proteasomal degradation. J Biol Chem. 2011;286(11):9598-9611.

19. Meissner M, et al. Moderate calcium channel dysfunction in adult mice with inducible cardiomyocyte-specific excision of the cacnb2 gene. J Biol Chem. 2011;286(18):15875-15882.

20. Cingolani E, Ramirez Correa GA, Kizana E, Murata M, Cho HC, Marbán E. Gene therapy to inhibit the calcium channel beta subunit: physiological consequences and pathophysiological effects in models of cardiac hypertrophy. Circ Res. 2007;101(2):166-175.

21. Kamp TJ, Hell JW. Regulation of cardiac L-type calcium channels by protein kinase $\mathrm{A}$ and protein kinase C. Circ Res. 2000;87(12):1095-1102.

22. Reuter $\mathrm{H}, \mathrm{Scholz} \mathrm{H}$. The regulation of the calcium conductance of cardiac muscle by adrenaline. J Physiol (Lond). 1977;264(1):49-62.

23. Katchman A, et al. Proteolytic cleavage and PKA phosphorylation of $\alpha 1 \mathrm{C}$ subunit are not required for adrenergic regulation of CaV1.2 in the heart. Proc Natl Acad Sci USA. 2017;114(34):9194-9199.

24. Brandmayr J, et al. Deletion of the C-terminal phosphorylation sites in the cardiac $\beta$-subunit does not affect the basic $\beta$-adrenergic response of the heart and the $\mathrm{Ca}(\mathrm{v}) 1.2$ channel. J Biol Chem. 2012;287(27):22584-22592.

25. Lemke T, et al. Unchanged beta-adrenergic stimulation of cardiac L-type calcium channels in Ca v 1.2 phosphorylation site S1928A mutant mice. J Biol Chem. 2008;283(50):34738-34744.

26. Ganesan AN, Maack C, Johns DC, Sidor A, O'Rourke B. Beta-adrenergic stimulation of L-type $\mathrm{Ca} 2+$ channels in cardiac myocytes requires the distal carboxyl terminus of alpha1C but not serine 1928. Circ Res. 2006;98(2):e11-e18.

27. Miriyala J, Nguyen T, Yue DT, Colecraft HM. Role of CaVbeta subunits, and lack of functional reserve, in protein kinase A modulation of cardiac CaV1.2 channels. Circ Res. 2008;102(7):e54-e64.

28. Chen YH, et al. Structural basis of the alpha1-beta subunit interaction of voltage-gated $\mathrm{Ca} 2+$ channels. Nature. 2004;429(6992):675-680.

29. Opatowsky Y, Chen CC, Campbell KP, Hirsch JA. Structural analysis of the voltage-dependent calcium channel beta subunit functional core and its complex with the alpha 1 interaction domain. Neuron. 2004;42(3):387-399.

30. Van Petegem F, Clark KA, Chatelain FC, Minor DL. Structure of a complex between a voltage-gated calcium channel beta-subunit and an alpha-subunit domain. Nature. 2004;429(6992):671-675.

31. Van Petegem F, Duderstadt KE, Clark KA, Wang $\mathrm{M}$, Minor DL. Alanine-scanning mutagenesis defines a conserved energetic hotspot in the CaValpha1 AID-CaVbeta interaction site that is critical for channel modulation. Structure. 2008;16(2):280-294.

32. He M, Bodi I, Mikala G, Schwartz A. Motif III S5 of L-type calcium channels is involved in the dihydropyridine binding site. A combined radioligand binding and electrophysiological study. J Biol Chem . 1997;272(5):2629-2633.

33. Hockerman GH, Peterson BZ, Sharp E, Tanada TN, Scheuer T, Catterall WA. Construction of a high-affinity receptor site for dihydropyridine agonists and antagonists by single amino acid substitutions in a non-L-type Ca2+ channel. Proc Natl Acad Sci USA. 1997;94(26):14906-14911.

34. Obermair GJ, et al. Reciprocal interactions regulate targeting of calcium channel beta subunits 
and membrane expression of alpha1 subunits in cultured hippocampal neurons. J Biol Chem. 2010;285(8):5776-5791.

35. Colyer J. Phosphorylation states of phospholamban. Ann N Y Acad Sci. 1998;853:79-91.

36. Gerhardstein BL, Puri TS, Chien AJ, Hosey MM. Identification of the sites phosphorylated by cyclic AMP-dependent protein kinase on the beta 2 subunit of L-type voltage-dependent calcium channels. Biochemistry. 1999;38(32):10361-10370.

37. Neuberger G, Schneider G, Eisenhaber F. pkaPS: prediction of protein kinase A phosphorylation sites with the simplified kinase-substrate binding model. Biol Direct. 2007;2:1.

38. Iakoucheva LM, et al. The importance of intrinsic disorder for protein phosphorylation. Nucleic Acids Res. 2004;32(3):1037-1049.

39. Zhou FF, Xue Y, Chen GL, Yao X. GPS: a novel group-based phosphorylation predicting and scoring method. Biochem Biophys Res Commun. 2004;325(4):1443-1448.

40. Blom N, Gammeltoft S, Brunak S. Sequence and structure-based prediction of eukaryotic protein phosphorylation sites. J Mol Biol. 1999;294(5):1351-1362.

41. Obenauer JC, Cantley LC, Yaffe MB. Scansite 2.0: Proteome-wide prediction of cell signaling interactions using short sequence motifs. Nucleic Acids Res. 2003;31(13):3635-3641.

42. Kushnir A, Shan J, Betzenhauser MJ, Reiken S, Marks AR. Role of CaMKIIdelta phosphorylation of the cardiac ryanodine receptor in the force frequency relationship and heart failure. Proc Natl Acad Sci USA. 2010;107(22):10274-10279.

43. Domes K, et al. Truncation of murine CaV1.2 at Asp-1904 results in heart failure after birth. J Biol Chem. 2011;286(39):33863-33871.

44. Fu Y, et al. Deletion of the distal $\mathrm{C}$ terminus of CaV1.2 channels leads to loss of beta-adrenergic regulation and heart failure in vivo. J Biol Chem. 2011;286(14):12617-12626.

45. Muth JN, et al. Cardiac-specific overexpression of the alpha(1) subunit of the L-type voltage-dependent $\mathrm{Ca}(2+)$ channel in transgenic mice. Loss of isoproterenol-induced contraction. J Biol Chem.
1999;274(31):21503-21506.

46. Beetz N, et al. Transgenic simulation of human heart failure-like L-type Ca2+-channels: implications for fibrosis and heart rate in mice. Cardiovasc Res. 2009;84(3):396-406.

47. Tang M, et al. Enhanced basal contractility but reduced excitation-contraction coupling efficiency and beta-adrenergic reserve of hearts with increased Cav1.2 activity. Am J Physiol Heart Circ Physiol. 2010;299(2):H519-H528.

48. Chen X, et al. Ca2+influx-induced sarcoplasmic reticulum $\mathrm{Ca} 2+$ overload causes mitochondrialdependent apoptosis in ventricular myocytes. Circ Res. 2005;97(10):1009-1017.

49. Chen $X$, et al. Calcium influx through Cav1.2 is a proximal signal for pathological cardiomyocyte hypertrophy. J Mol Cell Cardiol. 2011;50(3):460-470.

50. Maltez JM, Nunziato DA, Kim J, Pitt GS. Essential $\mathrm{Ca}(\mathrm{V})$ beta modulatory properties are AID-independent. Nat Struct Mol Biol. 2005;12(4):372-377.

51. Findeisen F, Minor DL. Disruption of the IS6AID linker affects voltage-gated calcium channel inactivation and facilitation. J Gen Physiol. 2009;133(3):327-343.

52. Fabiato A. Simulated calcium current can both cause calcium loading in and trigger calcium release from the sarcoplasmic reticulum of a skinned canine cardiac Purkinje cell. J Gen Physiol. 1985;85(2):291-320.

53. Negroni JA, et al. $\beta$-adrenergic effects on cardiac myofilaments and contraction in an integrated rabbit ventricular myocyte model. J Mol Cell Cardiol. 2015;81:162-175.

54. Aalkjaer C, Nilsson H. Vasomotion: cellular background for the oscillator and for the synchronization of smooth muscle cells. Br J Pharmacol. 2005;144(5):605-616.

55. Kushnir A, Betzenhauser MJ, Marks AR. Ryanodine receptor studies using genetically engineered mice. FEBS Lett. 2010;584(10):1956-1965.

56. Marx SO, et al. PKA phosphorylation dissociates FKBP12.6 from the calcium release channel (ryanodine receptor): defective regulation in failing hearts. Cell. 2000;101(4):365-376.
57. Wehrens XH, Lehnart SE, Reiken SR, Marks AR. $\mathrm{Ca} 2+$ /calmodulin-dependent protein kinase II phosphorylation regulates the cardiac ryanodine receptor. Circ Res. 2004;94(6):e61-e70.

58. Shan J, et al. Phosphorylation of the ryanodine receptor mediates the cardiac fight or flight response in mice. JClin Invest. 2010;120(12):4388-4398.

59. Muraski JA, et al. Pim-1 kinase antagonizes aspects of myocardial hypertrophy and compensation to pathological pressure overload. Proc Natl Acad Sci USA. 2008;105(37):13889-13894.

60. Eisner DA, Kashimura T, O’Neill SC, Venetucci LA, Trafford AW. What role does modulation of the ryanodine receptor play in cardiac inotropy and arrhythmogenesis? J Mol Cell Cardiol. 2009;46(4):474-481.

61. Sanbe A, Gulick J, Hanks MC, Liang Q, Osinska H, Robbins J. Reengineering inducible cardiac-specific transgenesis with an attenuated myosin heavy chain promoter. Circ Res. 2003;92(6):609-616.

62. Hambleton M, et al. Inducible and myocyte-specific inhibition of PKCalpha enhances cardiac contractility and protects against infarction-induced heart failure. Am JPhysiol Heart Circ Physiol. 2007;293(6):H3768-H3771.

63. Valencik ML, McDonald JA. Codon optimization markedly improves doxycycline regulated gene expression in the mouse heart. Transgenic Res. 2001;10(3):269-275.

64. Colecraft HM, et al. Novel functional properties of $\mathrm{Ca}(2+)$ channel beta subunits revealed by their expression in adult rat heart cells. J Physiol (Lond). 2002;541(Pt 2):435-452.

65. Yang L, Katchman A, Samad T, Morrow J, Weinberg $\mathrm{R}$, Marx SO. $\beta$-adrenergic regulation of the L-type $\mathrm{Ca} 2+$ channel does not require phosphorylation of a1C Ser1700. Circ Res. 2013;113(7):871-880.

66. O'Connell TD, Rodrigo MC, Simpson PC. Isolation and culture of adult mouse cardiac myocytes. Methods Mol Biol. 2007;357:271-296.

67. Xu X, Marx SO, Colecraft HM. Molecular mechanisms, and selective pharmacological rescue, of Rem-inhibited CaV1.2 channels in heart. Circ Res. 2010;107(5):620-630. 